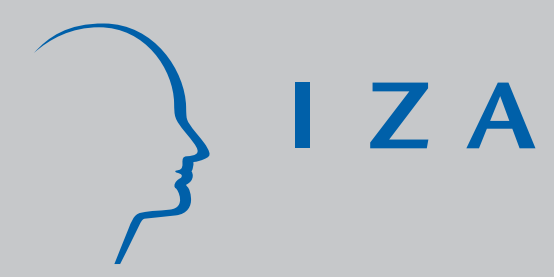

IZA DP No. 3001

A Demographic Analysis of the Family Structure Experiences of Children in the United States

David M. Blau

Wilbert van der Klaauw

August 2007 


\title{
A Demographic Analysis of the Family Structure Experiences of Children in the United States
}

\author{
David M. Blau \\ Ohio State University \\ and IZA \\ Wilbert van der Klaauw \\ Federal Reserve Bank of New York \\ Discussion Paper No. 3001 \\ August 2007 \\ IZA \\ P.O. Box 7240 \\ 53072 Bonn \\ Germany \\ Phone: +49-228-3894-0 \\ Fax: +49-228-3894-180 \\ E-mail: iza@iza.org
}

\begin{abstract}
Any opinions expressed here are those of the author(s) and not those of the institute. Research disseminated by IZA may include views on policy, but the institute itself takes no institutional policy positions.

The Institute for the Study of Labor (IZA) in Bonn is a local and virtual international research center and a place of communication between science, politics and business. IZA is an independent nonprofit company supported by Deutsche Post World Net. The center is associated with the University of Bonn and offers a stimulating research environment through its research networks, research support, and visitors and doctoral programs. IZA engages in (i) original and internationally competitive research in all fields of labor economics, (ii) development of policy concepts, and (iii) dissemination of research results and concepts to the interested public.
\end{abstract}

IZA Discussion Papers often represent preliminary work and are circulated to encourage discussion. Citation of such a paper should account for its provisional character. A revised version may be available directly from the author. 


\section{ABSTRACT}

\section{A Demographic Analysis of the Family Structure Experiences of Children in the United States ${ }^{*}$}

This paper provides a comprehensive demographic analysis of the family structure experiences of children in the U.S. Childbearing and transitions among co-residential union states defined by single, cohabiting, and married are analyzed jointly. A novel contribution is to distinguish men by their relationship to children: biological father or stepfather. This distinction is rarely made when analyzing union formation, but it is critical for understanding the family structure experiences of children. The analysis uses data from the 1979 cohort of the National Longitudinal Survey of Youth (NLSY79). The results are used to address the following issues: (1) What fraction of their childhood do children spend with the biological father, stepfathers, and no father? (2) How do these fractions vary by the mother's marital status at the time of the child's birth and at the time of the child's conception? (3) How do the family structure experiences of the children of white, black, and Hispanic mothers differ, and what are the proximate demographic determinants of these differences? A key finding is that children of black mothers spend on average only $34.1 \%$ of their childhood living with the biological father and mother, compared to $72.8 \%$ for whites and $64.1 \%$ for Hispanics. The two most important proximate demographic determinants of this large racial gap are the much higher propensity of black women to conceive children outside of a union, and the lower rate of "shotgun" unions for blacks compared to whites and Hispanics. Another notable finding is that cohabitation plays a negligible role in the family structure experiences of children of white and Hispanic mothers, and even for children of black mothers accounts for only one fifth of time spent living with both biological parents. Finally, we find that children of black, Hispanic, and white mothers spend similar proportions of their lives with stepfathers present, but this similarity masks a much higher stepfather "turnover" rate among blacks, who are more likely than the other groups to experience a larger number of shorter spells with different stepfathers.

JEL Classification: J10

Keywords: family structure, marriage, cohabitation, race, ethnicity

Corresponding author:

David M. Blau

Department of Economics

The Ohio State University

Arps Hall, 1945 N. High St.

Columbus, $\mathrm{OH} 43210-1172$

USA

E-mail: Blau.12@osu.edu

\footnotetext{
* Financial support from NICHD grant HD45587 is gratefully acknowledged. Thanks to Karin Gleiter for expert programming. A previous version of this paper was presented at the 2005 Annual Meeting of the Population Association of America in Philadelphia, and in seminars at the Carolina Population Center, Cornell, Syracuse, NYU, and the $2005 \mathrm{NIH}$ Workshop on Intergenerational Family Resource Allocation. We are grateful for comments by seminar and conference participants, particularly Suzanne Bianchi, Francine Blau, Larry Bumpass, and Larry Wu. The authors alone are responsible for the contents. The views expressed are those of the authors and do not necessarily reflect those of the Federal Reserve Bank of New York.
} 


\section{INTRODUCTION}

Many children growing up in the United States in recent decades have spent a significant part of their childhood living in families with structures different from the traditional one with two married biological parents. Major increases in divorce, out-of-wedlock childbearing, and cohabitation have resulted in rapid growth in the prevalence of alternative family structures. Such alternatives include living with the biological mother and the biological father in a cohabiting (unmarried) relationship, the biological mother and a step father, the biological mother and no man, and others. An important question of interest to social scientists, policy makers, and parents is how growing up in alternative family structures affects children, compared to the traditional experience of being raised by married biological parents. A large literature spanning several disciplines has analyzed the effects of children's family structure experiences on psychological, social, demographic, and economic outcomes, both during childhood and subsequently in adulthood. ${ }^{1}$

An important issue raised by such studies is what determines the family structure experienced by children during the course of their childhood. Factors that influence family structure may also have a direct impact on child outcomes, making it difficult to infer causality from correlations. But the family structure experiences of children are of independent interest as well. The proximate determinants of family structure are fundamental demographic behaviors: incidence and timing of childbearing, cohabitation, and marriage. A key point recognized in the

${ }^{1}$ Well-known examples include McLanahan and Sandefur (1994), Chase-Lansdale, Cherlin, and Kiernan (1995), and Hetherington and Stanley-Hagan (1999). Recent analyses include Aughinbaugh, Pierret, and Rothstein (2005), Gennetian (2005), Ginther and Pollak (2004), Hofferth (2006), Lang and Zagorsky (2001), and Sigle-Rushton, Hobcroft, and Kiernan (2005). 
literature is that the interaction between childbearing and marital behavior determines the family structure experienced by children. There are many studies of the demographic behaviors that influence family structure, including divorce, cohabitation, and out of wedlock childbearing. But these studies generally do not draw implications from their findings for the family structure experienced by children. This is because the latter requires an integrated analysis. For example, divorce presumably affects children differently if they were alive at the time of the divorce compared to being born after the divorce. Similarly, the impact on children of a cohabiting versus a married relationship between a child's biological parents may depend on whether the child was born before or during the cohabitation. The impact on a child of being born out of wedlock is likely to depend on whether the mother and biological father subsequently marry or cohabit, and if so, how soon after the birth of the child.

A handful of studies analyze the implications of marital and childbearing behavior for the family structure experiences of children. But these studies have taken a limited perspective because they typically analyze only a subset of the relevant behaviors. For example, some studies focus only on divorce (Waite and Lillard 1991) or formation of formal unions (Upchurch, Lillard, and Panis 2001), while others focus only on children who were born out of wedlock (Brien, Lillard, and Waite 1999; Aquilino, 1996; Carlson, McLanahan, and England, 2004). An important issue in analyzing demographic behavior from the perspective of children is the identity of the man with whom a mother lives. A woman who has given birth to a child outside of a co-residential relationship is at risk of entering a co-residential relationship with the father of the child and with other men. When analyzing relationship formation from the mother's perspective, this distinction is rarely made (Graefe and Lichter 1999 is an exception). It could be 
important for the durability of the relationship, and thus important to analyze from the mother's perspective. But it is critical for understanding the family structure experiences of children born outside of a co-residential union.

In this paper we provide a more comprehensive demographic analysis of the family structure experiences of children than has been reported in previous studies. We jointly analyze transitions among co-residential union states defined by single, cohabiting, and married, together with childbearing and the identity of men from the perspective of children: biological father or stepfather. Modeling transitions into and out of cohabitation, marriage, and single status jointly with childbearing behavior provides a richer picture of family dynamics than does analyzing marital behavior in isolation. And modeling the identity of men from the perspective of children provides a unique perspective on transitions of children among living arrangements.

The analysis uses data from the 1979 cohort of the National Longitudinal Survey of Youth (NLSY79). These data provide detailed histories of the relevant demographic events, and unlike most other demographic surveys, provide information on biological and non-biological fathers for each child. ${ }^{2}$ These data have been used in many previous analyses of family structure, but we exploit the richness of the data more fully than in previous studies, particularly the information on the identity of men from the perspective of children. Other important advantages

${ }^{2}$ See Andersson (2002) for a descriptive comparison of the family structure experiences of children in 15 countries, including the U.S. His findings show that "The USA stands out as one extreme case with its very high proportion of children born to a lone mother, with a higher probability of children who experience a union disruption of their parents than anywhere else, and with many children having the experience of living in a stepfamily." (Page 343). Heuveline et al. (2003) also report that the U.S. is an outlier in the sense that over half of all time spent by American children in single parent families is accounted for by children born to lone mothers. This true of only three countries in their 17-country sample. 
of the NLSY79 are that the data are prospective, and there are large enough samples to analyze whites, blacks, and Hispanics separately. The main disadvantage of the NLSY79 data compared to other commonly used data in the family demography literature is that while the mothers in the NLSY79 are a sample from a well-defined birth cohort (1957-1964), the children of mothers in the NLSY79 do not form a well-defined cohort: their birth dates range from 1970 through the present. Their only common link is that they were all born to women who are themselves part of a well-defined birth cohort. Thus the analysis includes children born over a long period of time, in which there were major changes in some of the demographic behaviors of interest. It is clearly inappropriate to use these data to draw inferences about cohort trends, but this is not our goal in any case.

Another contribution of our analysis is that we use the estimation results to simulate the life histories of women and their children. The advantage of the simulation approach over the life table approach commonly used in the demographic literature is that we can easily compute the entire distributions of outcomes of interest, rather than the limited set of outcomes that can be computed by solving matrix equations in the life table approach. Moffitt and Rendall (1995) use a simulation approach to deriving the implications of estimated transition rates of women in and out of family headship. They note that another important advantage of the simulation approach is that it easily accommodates arbitrarily complex forms of duration and occurrence dependence, which is not possible with life table methods. We extend their approach by deriving the implications for children as well as for women.

We use the results of our analysis to address a number of issues that have not previously been analyzed, as well as to provide new perspectives on previously-studied issues. These 
include: (1) What fraction of their childhood do children spend with the biological father, stepfathers, and no father? (2) How do these fractions vary by the mother's marital status at the time of the child's birth and at the time of the child's conception? ${ }^{3}$ (3) How do the family structure experiences of the children of white, black, and Hispanic mothers differ, and what are the proximate demographic determinants of these differences? The most striking finding is the large difference between the children of black and white mothers in time spent living with the biological father. Children of white mothers on average spend $73 \%$ of their childhood years living with their biological mother and father, compared to $34 \%$ for children of black mothers. Children of Hispanic mothers are closer to whites at $64 \%{ }^{4}$ It is also notable that the distribution of time spent living with the biological father is heavily skewed for children of black mothers: the median is only 1.2 years, and $44 \%$ of children of black mothers never live with the biological father. The distributions are much more symmetric for the children of white and Hispanic mothers. Surprisingly, estimates of the duration of childhood spent with both biological parents have not been presented previously.

One important source of the difference between blacks and whites is the role of the mother's status at the time of conception. For all three groups, the mother's marital status at birth plays a dominant role in determining time spent with the biological father during childhood. However, if the mother was single at the time the child was conceived, the percent of childhood spent with the biological mother and father together is $46 \%$ for whites, $14 \%$ for blacks, and $34 \%$

${ }^{3}$ The first two questions are descriptive, but can only be addressed with a model, due to censoring and missing data, described in detail below.

${ }^{4}$ Here and throughout the paper, whites and blacks include only non-Hispanics. Hispanics can be either white or black (or another race). 
for Hispanics. The black-white difference results from the fact that "shotgun" weddings and cohabitations are much more common for whites than for blacks and Hispanics (Manning, 2004; Manning, Smock, and Majumdar, 2004). Another important source of the difference is the higher propensity of black women to conceive children outside of a co-residential union. Many previous studies have discussed the implications of marital and childbearing behavior for the family structure experiences of children, but this is the first paper to directly model the implications of these adult demographic behaviors for the family structure experiences of children.

In the remainder of the paper we provide background for the analysis, discuss conceptual issues and the specification of the empirical model, describe the data, present the results, discuss the findings, and conclude.

\section{BACKGROUND}

Marriage has become much less common in the last 30 years in the U.S., as a result of both later age at marriage and an increase in the proportion of adults who never marry. In 1970, $10 \%$ of women aged 25-29 and 7\% of those aged 35-44 had never married; by 2000 these percentages were 52\% and 18\%, respectively (Fields and Casper 2001: Table 5). Many young unmarried adults live in cohabiting relationships. Ten percent of women aged 25-34 living with a man as a partner or spouse in March 2000 were unmarried. The proportion of people who lived in a cohabiting relationship before first marriage by age 25 rose from 11\% in 1970 to about 50\% in 1988 (Bumpass, Sweet, and Cherlin 1991).

While marriage has declined, divorce has increased substantially. Of women born from 1925 to $1934,12 \%$ had divorced by age 35, compared to $29 \%$ of women born from 1945 to 
1954. Eleven percent of the earlier cohort of women had ever been married more than once by age 40 , compared to $22 \%$ of the later cohort. Overall, in $199622 \%$ of women aged $15+$ had ever been divorced (Kreider and Fields 2002). Projections based on the cohort trends in these data indicate that slightly over half of recent marriages will end in divorce, and that over $80 \%$ of people who divorce will eventually remarry.

Births to unmarried women increased from 18\% of all births in 1980 to $33 \%$ in 2000 (Martin et al. 2002). The proportion of all births that occurred to unmarried women in 2000 by race and ethnicity was 22\% for non-Hispanic whites, $69 \%$ for blacks, and $43 \%$ for Hispanics. However, children born to unmarried women do not necessarily live with only one biological parent. Thirty-nine percent of births to unmarried women from 1990 to 1994 were to women in cohabiting relationships (Bumpass and Lu 2000). Thus while about half of children born recently are expected to ever spend time in a family with an unmarried parent (Cherlin 1999), many of these children are in fact living with both biological parents some of the time. Births to cohabiting women grew from $6 \%$ to $12 \%$ of all births from the early 1980 s to the early 1990 s.

Our analysis is most closely related to two previous papers: Brien et al. (1999), and Graefe and Lichter (1999). Brien et al. present an integrated analysis of non-marital conception, entry to cohabitation, and entry to marriage, using 1986 data from the National Longitudinal Study of the Class of 1972. The analysis is integrated in the sense that the effect of one type of behavior on the others is modeled. For example, they find that a non-marital conception greatly increases the risk of marriage during the pregnancy, but reduces the risk of marriage for women who do not marry quickly in response to conceiving a child out of wedlock (see also Bennett, Bloom, and Miller 1995). Their analysis controls for unobserved heterogeneity using a random 
effects approach, uses rich monthly histories, and a flexible specification of occurrence and duration dependence. Like Brien et al., we jointly analyze several key demographic behaviors, use rich multiple spell data, control for unobserved heterogeneity, and provide a flexible characterization of duration and occurrence dependence. We go beyond Brien et al. by (1) modeling union dissolution behavior and marital conceptions, (2) using prospective data that are less subject to recall error, (3) using data through 2002, and most important, (4) explicitly incorporating the identity of men in the analysis, thereby making possible inferences about the family structure experiences of children from an analysis of the behavior of mothers.

Graefe and Lichter (1999) analyze marital transitions from the perspective of children. They use data from the NLSY79 covering children born from 1980-1992 to model transitions of children from a single-mother family to cohabitation and marriage, and transitions from cohabitation to single and married. In the latter model, they include as a covariate an indicator of whether the cohabiting man is the biological father of the child. This may be different for different children in the family, hence the use of the child as the unit of analysis. They find that biological children are at much greater risk of transition from cohabitation to marriage and at lower risk of transition to single, compared to stepchildren. Their estimates imply that about $16 \%$ of children born to never-married mothers in this cohort will live with the mother's cohabiting partner during the first year of life, and 26\% by age 14. Many children living with cohabiting parents experience a transition into marriage: $35 \%$ within one year and $50 \%$ within five years (However, Raley 2001, finds that cohabiters with children have been less likely to marry in recent years than in the past). Like Graefe and Lichter, we focus on the identity of men with whom mothers cohabit and marry, i.e. their relationship to the woman's children. We go 
significantly beyond Graefe and Lichter by (1) accounting for the identity of men in analyzing transitions from single to cohabitation and marriage; (2) analyzing the determinants of step versus biological father status by modeling conceptions jointly with marital behavior; and (3) recognizing that while child characteristics can influence marital transitions, the appropriate unit of analysis for marital transitions is the mother, not the child. Thus we analyze the behavior of women, but our modeling approach enables us to draw inferences about the implications of their behavior for the family structure experiences of children. We also use monthly instead of annual data, extend the analysis back to include all births and forward through 2002, and account for unobserved heterogeneity.

\section{CONCEPTUAL ISSUES AND EMPIRICAL MODEL}

We focus on the marital and childbearing behavior of women. The behavior of men is obviously relevant, but the complexity of modeling male and female behavior jointly, as well as the limitations of the available data, necessitate a focus on the woman's perspective. We assume that women become at risk of entering a co-residential union and conceiving a child at age $12 .{ }^{5}$ We use a monthly discrete time framework. ${ }^{6}$ For empirical tractability, it is assumed that at most one demographic event can occur in a given month, where events include conceiving a child, giving birth, beginning a co-residential relationship, and ending a co-residential relationship.

${ }^{5}$ The youngest age at which a birth occurred in the sample was 11 , but we ignore the handful of births at age 11 here. The earliest age of entry into cohabitation in the sample is 13.25 and into marriage is 13.58 .

${ }^{6}$ Lillard's (1993) continuous time model of simultaneous hazards is in principle an attractive framework for the analysis. However, it is very difficult to deal with missing data in Lillard's model. We discuss below how missing data are handled. 
With periods of one month, it is rare for two events to occur in the same month. The advantage of this assumption is that it allows us to use a competing risks empirical model in which there is no chance that two or more events can occur in the same period. ${ }^{7}$

We consider three co-residential relationship states, which for brevity we refer to henceforth as union states: single, married, and cohabiting. Cohabiting is defined as living with an opposite sex partner in an unmarried relationship. If a woman was single in the previous period, her union choice set for the current period includes (1) remaining single, (2) entering a cohabitation, and (3) entering a marriage. If she was cohabiting in the previous period, then her union choice set includes (1) ending the relationship and becoming single, (2) continuing the cohabitation, and (3) converting the cohabitation into a marriage. If the woman was married in the previous period, then her union choice set is to end the marriage and become single, or continue the marriage: a marriage cannot turn into an unmarried cohabitation, and she cannot switch from one man to another in the same month. Because we are interested in the implications of marital behavior for the family structure experience children, the end of a marriage is defined to occur at the time of separation rather than divorce. However, some separations are temporary, and modeling the process that determines whether a separated couple reunites would make the analysis overly complex. Therefore, we ignore separations that result in reuniting rather than divorce, if the temporary separation lasts less than two years. If a temporary separation lasts

${ }^{7}$ The assumption that at most one event occurs per month implies that a woman cannot end a co-residential relationship with one man and begin a co-residential relationship with another man in the same month. A new co-residential relationship can be formed only if the woman is single at the beginning of the month. And a newly formed co-residential relationship cannot be dissolved in the period in which it was formed. Hence, we assume that all partnerships last at least one month, and all single spells last at least one month. 
more than two years, we censor the observation at the date of separation. We also allow for transitory separations involving cohabitation, again if the separation lasts no more than two years.

We consider only conceptions that lead to a live birth. The focus of the analysis is the family structure experiences of children, so pregnancies that do not result in a live birth are not of direct interest. ${ }^{8}$ If a conception leading to a live birth occurs, the duration of the pregnancy is taken as given. Thus, while conception is a risk in the model, conditional on conceiving a child birth is not a risk. A mother is at risk of changes in her union status while pregnant, but birth itself is treated as an exogenous censoring event that ends a pregnant spell. Thus, the timing of births, conditional on the date of conception, is taken as given. The occurrence of twin births is also taken as given.

The most novel aspect of our analysis is the focus on the identity of men. The relevant issues are (1) whether a newly formed union is with a man who has previously fathered any of the woman's children, and (2) whether a newly conceived child was fathered by the same man who fathered the woman's youngest child, if any. These factors determine whether a given child lives with - or is at risk of living with - his biological father or a stepfather. Note that stepfather here means a co-residing man who is not the child's biological father, regardless of whether the union is a cohabitation or a marriage. One key assumption is invoked in order to make the analysis tractable: if a woman ends a union with a given man, she is not at risk of conceiving a

\footnotetext{
${ }^{8}$ Ignoring pregnancies that do not lead to a live birth results in some women being treated as if they were at risk of conception in some months in which they actually are pregnant. And the occurrence of a miscarriage or abortion could affect the demographic processes of interest. Accounting for pregnancies that do not result in a live birth would require modeling at least two additional events - miscarriage and abortion - in an analysis that is already quite rich.
} 
child or entering a union again with that man. ${ }^{9}$ Without this assumption, it would be necessary to keep track of all men with whom a woman ever lived or who fathered any of her children, because she would be at risk of entering a relationship or conceiving a child with all such men.

With this assumption, we can limit attention to at most two men in any given period. One is the current man, defined as the partner or spouse if in a union, or, if single, the father of the woman's most recent child born since the end of the last union (or since she began bearing children if she has never been in a union; this will be implicit henceforth). The other man is a new man, defined as a man who has not fathered any of her children and with whom she has never lived. For a woman in a union, only the current man is relevant: if she lives with a man in month $t-1$, that man is by assumption the only man with whom she can live and conceive a child with in month $t$. For a single woman with no children born since the end of the last union, only the new man is relevant: there is no current man. If she enters a union or conceives a child, it must be with a new man. For a single woman who has given birth to at least one child since the end of her most recent union, both the current man and a new man are relevant. If she enters a new union, it matters whether it is with the current man, because in this case some of her children will have their biological father present. Alternatively, if the relationship is with a new man, then all of her children will have a stepfather present. And if she conceives a child with the current man, the number of children at risk of living with the biological father in the event of a future union with this man increases by one. If the conception is with a new man, then children fathered by any previous men are (by assumption) no longer at risk of living with the biological

${ }^{9}$ Note that this assumption does not rule out a woman having multiple children with a given man with whom she does not live. Such behavior is ruled out only if the woman bears a child with a different man between pregnancies with the man in question. 
father in the event of a future union. ${ }^{10}$

In order to describe the model more formally, let $B_{\mathrm{t}}$ denote the number of children born to a single woman since the end of the previous union, and define $N_{t}=0$ if a single pregnant woman with $B_{\mathrm{t}}>0$ is pregnant with the current man, and $N_{t}=1$ if she is pregnant with a new man. In any given month, a woman is at risk of one or more of the following events:

1. conceiving a child with the current man

2. conceiving a child with a new man

3. ending a union and becoming single

4. entering a cohabitation with the current man

5. entering a cohabitation with a new man

6. marrying the current man

7. marrying a new man

A state is defined by the unique set of risks to which a woman is subject. The set of risks she faces depends on her pregnancy status, marital status, $B_{t}$, and $N_{t}$. Table 1 identifies eight states defined by the unique set of risks to which a woman is subject. In states $1-4$, she is not pregnant, and is therefore at risk of conceiving a child. In states 5-8 she is pregnant and is not at risk of conceiving. In states $1,2,5$, and 6 , she is single and is therefore at risk of entering a cohabitation or marriage. In state 1 there is no current man $\left(B_{t}=0\right)$, so the relationship or conception can only

\footnotetext{
${ }^{10}$ Note that the new man this period could be different from the new man in previous
} periods. There is no way to determine this empirically, because we know nothing about non-coresidential romantic relationships unless and until they become co-residential. For example, we do not know how long a woman may have been dating a given man. This could be relevant in determining the risk that he fathers a child or enters a union with the woman. See Carlson et al. (2004) for an analysis of this issue using data from the Fragile Families study. 
be with a new man. In state 2 there is a current man $\left(B_{t}>0\right)$ : the father of the most recent of the $B_{t}$ children born since the end of the previous union, so she is at risk of entering a relationship or conceiving a child with both the current man and a new man. In state $5, B_{t}>0$ and the father of the child with whom she is pregnant is the current man. Thus she is at risk of entering a relationship with the current man only. In state 6, she may or may not have given birth to any children since the end of the previous union, but the father of the child with whom she is pregnant is a new man, so she is at risk of entering a relationship only with this new man (who becomes the current man upon conception of the child). In states 3 and 7 she is cohabiting, and is at risk of marrying the current man and ending the relationship. In states 4 and 8 she is married and is at risk of ending the relationship.

We specify an index function $h_{j s}(t)$ for the occurrence of the $j^{\text {th }}$ event $(j=1, \ldots, 7)$ in month $t$ while in state $s(s=1, \ldots, 8)$. Note that not all risks are relevant in each state; Table 1 shows the relevant risks for each state. We assume that

$$
h_{j s}(t)=Z(t) \alpha_{j s}+X \beta_{j s}+\varepsilon_{j s t}
$$

where $Z(t)$ is a vector of polynomials in duration and age effects (duration of the current union status, duration of pregnancy, duration since previous birth, mother's age, etc.), $X$ is a set of variables that are constant within a spell in a given state (e.g., number of children, number of children with biological father present, marital status, race), $\alpha_{\mathrm{js}}$ and $\beta_{\mathrm{js}}$ are coefficient vectors, and $\varepsilon_{\text {jst }}$ is a disturbance. Within a spell, all durations and ages are perfectly collinear, but the $\alpha_{\text {js }}$ coefficients are identified by variation across spells in the calendar month of the begin date of the spell and by the existence of multiple spells in a given state. Additive separability of $Z(t)$ and $X$ is not crucial, and is selectively relaxed in the empirical analysis. This expression for $h_{j s}(t)$ can 
be interpreted as an approximation to the combination of decision rules and stochastic processes that determines the risk of occurrence of the $j^{\text {th }}$ event while occupying state $s$. The value of alternative marital and fertility choices will depend on the woman's marital and fertility history if these affect the flow of utility she receives from the alternative choices or if they affect her expectations about future outcomes. Hence, $X$ includes measures of her marital and fertility history. The value of the alternative choices may depend on other observable factors such as her age and race, for similar reasons. The value of alternative choices will also depend on unobserved factors, such as the characteristics of her current partner, the perceived state of the marriage market, her expectation about the effects on her children of alternative marital choices, etc. These are captured by $\varepsilon_{j s t}$. Note that this specification is very flexible: the effects of all state variables can vary freely with the state occupied, that is with the combination of union status, pregnancy status, and “man” status.

The disturbance $\varepsilon_{\text {jt }}$ is specified as $\varepsilon_{\text {jst }}=\rho_{\text {js }} \mu+\eta_{\text {jst }}$ where $\mu$ is a permanent error component, $\rho_{\mathrm{js}}$ is an event-and-state-specific factor loading, and $\eta_{\mathrm{jst}}$ is an independently and identically distributed error component that is assumed to follow a Type I extreme value distribution. It is important to allow for unobserved heterogeneity in order to capture persistence in unobserved factors such as those described above. Ignoring such persistence would result in the $Z(t)$ and $X$ variables picking it up, and would lead to invalid causal interpretations of correlations between current and previous marital and fertility behavior. For example, women who have children at a young age may be quite different in unobserved ways from women who delay childbearing, and $\mu$ will help control for such differences. The extreme value assumption is convenient, because the resulting event probabilities have the multinomial logit form, 
conditional on $\mu$. There are eight alternatives in total, including the null choice of doing nothing, but the choice set available in a given period depends on the state occupied in the period, as illustrated in Table 1. It is assumed that $\mu$ has a discrete step function distribution with two mass points, resulting in a mixture model. Given the large number of parameters estimated, it is not feasible to allow for a richer distribution for $\mu$. The logit model is estimated by maximum likelihood, integrating $\mu$ out of the likelihood function.

\section{DATA}

The NLSY79 cohort contains individuals born from 1957 to 1964. They were interviewed annually from 1979-1994 and have been interviewed biannually since 1994. We use data through the 2002 interview. The NLSY79 includes a representative cross-section sample and supplementary over-samples of blacks, Hispanics, low-income whites, and members of the armed forces. The armed forces sample was dropped in 1984 and the low-income white sample was dropped in 1990. Both of these groups are excluded from the analysis, but the black and Hispanic over-samples are retained. ${ }^{11}$ The original sample contained 6,283 women, and after dropping the low-income white and military samples there are 4,926 women.

The NLSY79 data provide four advantages for the analysis, compared to other possible data sources. First, the data provide information on all of the key behaviors of interest, including the identity of men from the perspective of children. The data on the identity of men are not perfect (see below), but the NLSY79 is the only nationally representative data that provide this

\footnotetext{
${ }^{11}$ Dummy variables for blacks and Hispanics are included in the analysis, so there is no need to use sample weights to adjust for over-representation of these two groups.
} 
information along with the other key variables: marriage and cohabitation histories, birth histories, and child co-residence histories. Second, the data are prospective, with only one or two years between surveys. Many other data sources used in the family demography literature are retrospective, and are likely to provide less accurate information on events such as cohabitation beginning and ending dates. Third, there are large enough samples to analyze whites, blacks, and Hispanics separately. The well-known differences in behavior between black and white women in particular makes this especially important. ${ }^{12}$ Finally, the NLSY79 is exceptionally rich in measures of child outcomes, both during childhood and young adulthood. The present paper is part of a project another aim of which is to evaluate the effects of family structure experiences of children on subsequent outcomes.

The NLSY79 data have one main disadvantage compared to other commonly used data in the family demography literature, such as the National Survey of Families and Households (NSFH) and the National Survey of Family Growth (NSFG). The NLSY79 follows a birth cohort of women and the children born to these women. The children themselves do not form a welldefined cohort: their birth dates range from 1970 through 2002 (and beyond), and their only common link is that they were all born to women who are themselves part of a well-defined birth cohort. Thus the analysis includes children born over a long period of time, in which there were major changes in some of the demographic behaviors of interest. It is clearly inappropriate to use these data to draw inferences about cohort trends, but this is not our goal in any case. Where

\footnotetext{
${ }^{12}$ In practice, we do not allow all parameters to vary for whites, blacks, and Hispanics. Preliminary estimates revealed that many parameters did not differ significantly across groups, so in order to avoid estimating an excessively large number of parameters we retained only those interactions that seemed to be quantitatively important. Intercept shifts and interactions with the current state were retained in all cases (except one, due to lack of convergence).
} 
possible, we compare our findings to those based on other data sources.

In 1979, the survey collected information on the beginning and ending dates (to the nearest month) of up to two marriages. In subsequent waves, information has been collected on up to three changes in marital status that occurred since the previous interview. Changes include marriage, separation, re-uniting after a separation, divorce, death of a spouse, and re-marriage. As noted above, we treat the date of separation as the end of a marriage, but temporary separations of less than two years are ignored. Cases in which a temporary separation lasted more than two years are censored at the date of separation ${ }^{13}$.

The survey has collected information on cohabitation in several different ways:

(1) At each interview date, the respondent is queried about her relationship to other members of her household. Included among the relationship codes in the resulting household roster are "partner” and "other non-relative.” The NLSY79 staff used this information together with the name, age, and marital status of each household member to uniquely identify all cohabiting partners ever listed in any interview. This provides a snapshot of cohabitation as of each survey date, but misses short cohabitations that began and ended between interviews, and does not permit identification of the month in which a cohabitation began or ended.

(2) Beginning in 1990, respondents were asked to report the date on which the

${ }^{13}$ The only exception to this rule is if the woman had not conceived any children before the end of the separation. Temporary separations are a problem because the presence of the father is mis-measured. If no children have been conceived, there is no problem. The date of separation was not ascertained for marriages that ended in divorce before the 1979 interview. We use the date of divorce as the ending date of the marriage in these cases (2.4\% of first marriages). In the sample of 4,926 women, there were 1,676 separations, of which $19 \%$ were temporary. The median duration of a temporary separation is 17 months, and $60 \%$ were shorter than two years and therefore ignored. The other $40 \%$ were censored. 
cohabitation began for cohabitations that were in progress at the interview date. Also, if a respondent is married at the interview date, she is asked whether she lived with her spouse before the marriage began, and if so when the cohabitation began. These questions elicit a more precise date for the beginning of a cohabitation, but the information is based on recall. We checked the recall data against cohabitations reported in progress at the survey date, and found many discrepancies. Hence, we used this more precise recall information to date the beginning of a cohabitation only if it did not conflict with the contemporaneously reported information. ${ }^{14}$

(3) Finally, the cohabitation questions were completely redesigned in the 2002 interview. For the first time, both the beginning and ending date of cohabitations that did not turn into marriages were ascertained. And cohabitations that lasted less than three months are ignored. We combined information from the interview date, the retrospective reports, and the 2002 interview to form as complete a cohabitation history as possible. The beginning and ending dates of many cohabitations could be identified only to the nearest survey date. Rather than discard such cases, we include them in the analysis and modify the likelihood function to account for the lack of precise beginning and ending dates. If we know that a cohabitation began sometime between the 1986 and 1987 interview dates, for example, the likelihood function includes terms for each of the possible beginning months, weighted by the probability that the cohabitation began in the given month. This uses the available information as efficiently as possible. The details of how the likelihood function accounts for uncertain cohabitation begin and end dates are in an unpublished appendix available on request. Sixty percent of freestanding

${ }^{14}$ Fifteen percent of freestanding cohabitations (those that did not subsequently result in a marriage) had recall-based information that conflicted with contemporaneous reports, and 30\% of cohabitations that turned into marriages had this problem. 
cohabitations had a beginning date that was not known to the nearest month, and 95\% had an uncertain end date. Forty percent of cohabitations that turned into marriages had an uncertain begin date (the end date in this case is the date of marriage, which is always known to the nearest month) ${ }^{15}$

The cohabitation and marriage histories were combined to form a complete union history. An extensive set of edits and checks were implemented in order to detect and correct problematic union histories. As a result, we were able to correct and retain many cases that otherwise would have been dropped. Nevertheless, we dropped 415 cases in which there were important inconsistencies in the union history that could not be resolved. These include marriages reported to have ended before they began, separations reported to have begun when the woman was not married, marriages that began before the previous marriage ended, cohabitations that turned into marriages with a different man, and so forth. ${ }^{16}$

The month and year of birth of each child is reported by the respondent. Beginning in 1984, women were asked when each pregnancy began. We use this information to identify the month of conception. If the information is missing, we assume the conception occurred 9 months

\footnotetext{
${ }^{15}$ Another consequence of the fact that some cohabitation dates are not known to the exact month is that there are cases in which the sequence of events cannot be determined. For example, if a cohabitation began sometime between the 1986 and 1987 interview dates and a birth also occurred in this interval, then we do not know whether the woman was single or cohabiting at the time of the birth. Ambiguity about the sequence of events occurs at least once for $9 \%$ of women in the sample. Rather than discarding such cases, we modify the likelihood function to account for all the possible sequences in which events could have occurred, weighted by the probability of each sequence. The details are available in the unpublished appendix.

${ }^{16}$ We drop another 12 cases in which more than one event occurred in the same month, such as a marriage that began and ended in the same month, or a child was conceived in the same month in which a relationship began or ended.
} 
prior to the birth. ${ }^{17}$ The date of death is ascertained to the month for the 130 children (1.6\%) who died. We drop two cases in which a birth occurred before age 12, and 6 cases in which the date of a child's death is reported to be before the child was born. Child deaths are treated as exogenous censoring events. The spell in progress at the time a child died is censored, and a new spell begins, with one less child.

Identifying fathers is one of the critical tasks. Beginning with the 1984 interview, the mother is asked for every biological child present in her household whether the biological father of the child is present. Thus, when a woman lives with a man before or during the conception or birth of a child, identifying fathers is straightforward. The more difficult cases are those in which a woman conceives and bears a child while single. In such cases, we need to identify whether the father of the child was the current man or a new man, but this is possible only if she subsequently moves in with a man. If she never enters a union with a man following the birth of a child, we cannot determine whether the father of that child was the current man or a new man. Similarly, following the birth of a child while single, if she moves in with a man and the union ends before the 1984 interview, then we cannot determine whether the father of that child was the current man or a new man. And if a man moves in and out between interviews, we cannot determine the father of the child. Of the 1,086 cases in which a child was conceived and born to a single woman who had given birth to a child since the end of her previous union, we are able to identify whether the father is the current man or a new man in 35\% of the cases. Rather than

${ }^{17}$ Sixty percent of live births had an observed conception date. For these cases, the birth occurred 9 months after the conception in 55.4\% of cases, 8 months after in $30.5 \%$ of cases, and 10 months after in $7.5 \%$ of cases. Thus the assumption of 9 months will usually be quite accurate, but we could misclassify some cases in relation to union beginning and ending dates. 
discard the remaining cases, we again modify the likelihood function to account for both possibilities, weighted by the probability that the father was the current man or a new man. The details of this approach are available in the unpublished appendix.

Finally, at each interview date we can determine from the household roster whether a given child is present in the mother's household. We do not model the processes that determine whether children move in and out of the mother's household. If a child moves out of the mother's household, the spell in progress is censored at the date of the last interview in which the child was known to be present, and a new spell begins with one less child present. If the child subsequently moves back in, the spell in progress is censored at the last date at which a child was known to be living outside the mother's household, and a new spell begins. We treat cases in which a child is away at school or living part-time with the mother as if the child is living with the mother. Eighteen percent of children ever move out before age 18, and $60 \%$ of those children ever move back in before age 18.

After dropping cases with inconsistent union histories, event histories that violate the assumptions of our model, and a few other cases with problematic data, we are left with a sample of 4,480 women out of 4,926. ${ }^{18}$ These women bore 7,970 children as of their latest interview or

\footnotetext{
${ }^{18}$ Cases that violate the assumptions of the model include women who (1) end a marriage or cohabitation with a man, and subsequently form a new co-residential union with the same man (except cases of temporary separation, as discussed above); (2) women who bear a child with one man, then with a second man, and then with the first man; and (3) cases in which two or more demographic events occur in the same month (e.g. marriage and birth; conception and exit from cohabitation). There were 114 cases in which a woman apparently violated assumption (1) and otherwise would have been kept in the sample; 68 cases in which a woman apparently violated assumption (2); and 65 cases in which assumption (3) was apparently violated. We say "apparently" because it is likely that some of these cases are a result of errors in identifying men, but there is no way to determine this.
} 
as of the date at which their event history was censored. The average age at the last date of observation is 38.7, and $74 \%$ of the sample was interviewed in 2002. Table 2 summarizes the union and childbearing behavior of the sample, separately for white, black, and Hispanic women. ${ }^{19}$ There are large differences between blacks and whites in union and childbearing patterns, with Hispanics usually falling in between and closer to whites. $88.6 \%$ of white women, $61.2 \%$ of black women, and $80.7 \%$ of Hispanic women ever married as of the last observation. Of women who ever married, $37.2 \%$ of whites, $52.3 \%$ of blacks, and $42.1 \%$ of Hispanics ever ended a marriage (divorced or permanently separated). $25.4 \%$ of the white sample ever experienced the end of a marriage when children were present, compared to $41.7 \%$ of blacks and $31.9 \%$ of Hispanics. $60.5 \%$ of white women who experienced the end of a marriage ever remarried, compared to $30.0 \%$ of blacks and $49.3 \%$ of Hispanics. The marriage patterns for this cohort of women in the NLSY79 are quite similar to the patterns for this cohort reported in other data sources (Hughes and Waite, 2007). $42.2 \%$ of whites, $34.6 \%$ of blacks, and $37.3 \%$ of Hispanics ever cohabited. These percentages are in the same range as those reported in Bumpass and Lu (2000) using data from the NSFH and NSFG. 74.5\% of cohabitations of whites ended with a transition to marriage, compared to $59.1 \%$ for blacks and $64.3 \%$ for Hispanics.

The mean number of children ever born is 1.69 for whites, 1.87 for blacks, and 1.98 for Hispanics. $21.7 \%$ of whites, $18.2 \%$ of blacks, and $16.9 \%$ of Hispanics were childless as of the last date of observation. $21.7 \%$ of whites ever conceived a child while single, compared to

\footnotetext{
${ }^{19}$ As discussed above, cases in which the sequence of events is uncertain are included in the analysis. They contribute terms in the likelihood function for all possible sequences, weighted by the estimated probability from the model of each alternative sequence. The descriptive statistics presented in Tables 2 and 3 weight each alternative possible sequence equally.
} 
$63.9 \%$ of blacks and $37.4 \%$ of Hispanics. $10.7 \%$ of whites ever gave birth to a child while single, compared to $58.4 \%$ of blacks and $26.0 \%$ of Hispanics. These rates are somewhat lower than the period rates for 2000 (Martin et al., 2002). Only 7-9\% of women ever conceived a child while cohabiting, while $4.0 \%$ of whites, $7.6 \%$ of blacks, and $7.9 \%$ of Hispanics ever gave birth while cohabiting. ${ }^{20}$ These figures illustrate the importance of using monthly data in order to capture union formation and dissolution events that occur during pregnancy. "Shotgun" union formation appears to be quite important for whites: about one half of white women who conceived a child while single were no longer single by the time of the birth. Shotgun unions are also a significant phenomenon for Hispanics, but less so for blacks. The data also show that a sizeable fraction of cohabitations convert to marriages following conception. $36.5 \%$ of white women ever experienced an episode of being single with children, compared to $82.3 \%$ of black women and 52.4\% of Hispanic women. $24.2 \%$ of whites, $35.6 \%$ of blacks, and 29.5\% of Hispanics ever had an episode in which a child had a stepfather present.

Table 3 summarizes family structure experiences from the perspective of children, based on data up to the last age observed or the month in which the child turned age 18, whichever comes first. $15.7 \%$ of children of white mothers were conceived while the mother was single, compared to $63.9 \%$ of children of black mothers and $27.5 \%$ of children of Hispanic mothers. $52.2 \%$ of children of white mothers who were conceived while single were born in a union, most in a marriage, compared to $10.2 \%$ of children of black mothers and $31.3 \%$ for Hispanics. This again highlights the prevalence of "shotgun" marriages for whites, and their relative infrequency

\footnotetext{
${ }^{20}$ Data from the early 1980 s show that 4,13 , and $10 \%$ of births were to cohabiting women, for whites, blacks, and Hispanics, respectively (Bumpass and Lu, 2000). The comparable figures for the early 1990 s were 9,16 , and 17 , respectively.
} 
among blacks (see Bumpass and Lu, 2000, for estimates of cohort trends). $30.1 \%$ of children of white mothers ever experienced an episode in which they lived with the mother without any man, compared to $75.7 \%$ of children of black mothers and $43.3 \%$ of children of Hispanic mothers. $17.1 \%$ of children of white mothers, $26.8 \%$ of children of black mothers, and $22.6 \%$ of children of Hispanic mothers ever lived with a step father. The higher incidence for blacks is consistent with the findings of Bumpass, Raley, and Sweet (1995). 94.0\% of children of white mothers, $51.6 \%$ of children of black mothers, and $84.7 \%$ of children of Hispanic mothers ever lived with their biological father. Of children whose biological father was not present at birth, the biological father moved into the child's household in $25.4 \%, 15.3 \%$, and $20.2 \%$ of cases for children of white, black, and Hispanic mothers, respectively. Of children whose biological father was ever present in the child's home, the father moved out of the child's household in 24.3\%, 43.8\%, and 29.6\% of cases for children of white, black, and Hispanic mothers, respectively. Of children who ever lived without a man present, a step father moved into the household in 53.0\%, 36.2\%, and 51.5\% of cases for children of white, black, and Hispanic mothers, respectively. 36.4\% and 36.0\% of children of white and Hispanic mothers who ever have a stepfather present experience the exit of the stepfather, compared to $49.4 \%$ of children of black mothers.

\section{RESULTS}

We estimated many different specifications of the model, with the goal of finding a reasonably parsimonious specification that could reproduce key patterns observed in the data. The specification reported here does not include any family background variables, so the effects 
of race and ethnicity may operate in part through associations with such variables. The covariates included are the mother's date of birth, duration of the current union status, the cumulative number of cohabitations and marriages, the type of the previous union if single and previously in a union, duration of pregnancy, age of the mother, age of the youngest and oldest children, number of children ever born, number of children fathered by the current man, and the number of children born since the end of the previous union (if single). As indicated in equation (1) all parameters are allowed to differ by the current state. However, we found that many covariates could be excluded from the specification for particular transitions without affecting the fit of the model at all.

The estimated logit coefficients are presented in the Appendix in Table A-1. The coefficients are not particularly informative, so we do not discuss them in detail. It is worth noting, however, that race effects are important, as expected: only 3 out of 21 intercept shifts are not significantly different from zero at the $5 \%$ level for blacks. The pattern of coefficient estimates on the black indicator is as expected given the discussion of the descriptive statistics above. Differences between Hispanics and whites are less significant: the majority of the intercept shifts for Hispanics are not significantly different from zero.

In order to illustrate the implications of the estimates, we used them to simulate the life histories of 50,000 artificial women who are subject to the risks characterized by the model. Each woman starts at age 12 in the single state with no children (state 1). The estimated parameters for state 1 are used to compute the probability of each of the three events that can occur to a woman in state 1 . A random number generator determines which, if any, event occurs. If the woman experiences an event, she changes states accordingly. If the event is conceiving a 
child, a pregnancy duration is randomly assigned according to the observed distribution of pregnancy durations in the sample (see note 16). If no event occurs, she remains in state 1 . The state variables are updated according to which event, if any, occurred, and the process is repeated for the next month. If pregnant, the birth occurs at the assigned duration. The process continues to age 39 of the woman. ${ }^{21}$ Simulations are computed separately for whites, black, and Hispanics, in each case integrating over the estimated heterogeneity distribution.

Table A-2 in the Appendix compares selected statistics from the data with their counterparts from the simulations, by race and ethnicity. In general, the model does a good job of reproducing key patterns in the data. Fertility, union status at conception and birth, shotgun cohabitations and marriages, and lifetime incidence of residence with biological and step fathers are predicted well. The model is less accurate in reproducing lifetime cohabitation, marriage, and divorce patterns, but is generally within 5-10 percentage points of the data. The model is least accurate in reproducing lifetime transition patterns, shown in the last four rows of Table A-2. For example, the conditional lifetime incidence of a stepfather moving in is over-predicted by 18-29 percentage points. A likely reason for this is the different treatment in the descriptive statistics (the "data" columns in Table A-2) and the estimation of cases in which the sequence of events is uncertain. In computing the statistics shown in the data column, all feasible sequences in uncertain-sequence cases are equally weighted (see the notes to tables 2 and 3), which

\footnotetext{
${ }^{21}$ The sample includes women up to age 45 , but the average age at the last observation is about 39. The simulations are truncated at age 39 in order to allow a comparison to the data. As in the data, some children are not observed for their entire childhood in the simulations. The simulated data for children are truncated at age 18, as were the real data. In the simulations, there are no deaths or children who move in or out of the mother's household. The only exogenous explanatory variable other than race/ethnicity is the woman's date of birth, which is set to the sample mean for all women in the simulations.
} 
implicitly assumes that events are independently and uniformly distributed across calendar months. In the model, they are weighted according to the estimated likelihood of their occurrence, based on the complete observed event histories. The large differences suggest that for the cases with no uncertainty about the sequence of events, the assumption of independent uniform distribution is violated. The model estimates account for this violation but the descriptive statistics do not. Thus, the failure of the model to accurately fit some of the patterns in the data does not necessarily reflect poorly on the model..$^{22}$ In any case, the overall patterns predicted by the model are in general close to those seen in the data.

We use the simulations to illustrate patterns of family structure and transitions experienced by children, since this represents the novel contribution made possible by our analysis. Figure 1a shows the simulated mean cumulative duration of time spent with the biological father from birth through the $18^{\text {th }}$ birthday, separately for children of white, black, and Hispanic mothers. ${ }^{23}$ Children of white mothers can expect to spend about 11 years with the biological father by age 18, compared to 9 years for children of Hispanic mothers, and 4 years for children of black mothers. Thus even for children of white mothers, on average only $61 \%$ of childhood is spent with the biological father through age 18. The white-Hispanic difference of 2 years is sizeable, but the 7 year difference between blacks and whites is enormous. This

\footnotetext{
${ }^{22}$ We re-estimated the model using only the sub-sample of cases in which there was no uncertainty about the sequence of events. Comparing descriptive statistics and model predictions for this sub-sample shows that 71\% of the cases in Table A-2 with a difference of more than 5 percentage points between the data and model have a better fit, in many cases substantially better. This confirms the importance of proper weighting in the estimation.

${ }^{23}$ It is implicit here and throughout the remaining discussion that the child lives with the biological mother. Hence, "time spent with the biological father" means "time spent with the biological father and mother together.”
} 
difference is implied by well-documented differences in racial patterns of union formation, dissolution, and childbearing, but has never previously been directly illustrated. Even more striking than differences in the means are differences in the skewness of the distributions. Table 4 summarizes the distribution of lifetime years spent with the biological father as of the last age observed for each child. $44 \%$ of children of black mothers are estimated to never live with their biological father during childhood, compared to $6 \%$ of children of white mothers and $14 \%$ of children of Hispanic mothers. We are not aware of any previous studies that have presented information on the distribution of childhood spent with the biological father, stepfathers, and no father figure.

The remaining panels of Figure 1 illustrate the impact of the mother's marital status at birth and at conception on time spent with the biological father. Marital status at birth is clearly the major determinant of time spent with the biological father, but it is not the only determinant. If the mother was single at the time the child was born, the mean percent of childhood spent with the biological father is $20 \%$ for whites, $11 \%$ for blacks, and $16 \%$ for Hispanics. Marital status at the time of conception plays a dominant role in family structure experiences for children of black mothers, but much less so for children of white and Hispanic mothers. If the mother was single when the child was conceived, the mean percent of childhood spent with the biological father is $46 \%$ for whites, $15 \%$ for blacks, and 33\% for Hispanics. This is due to the fact that "shotgun" weddings and cohabitations are much more common for whites and Hispanics than for blacks (see Table 3).

Figure 2 summarizes the underlying transition patterns for entry and exit of the biological father from the child's home, aggregated to the annual level. The annual rate of entry of the 
biological father to the child's household (for children at risk of this event) is 8-9\% for children of white and Hispanic mothers during the first year of life, versus 5.5\% for blacks. The rate drops rapidly with age and converges for all three groups to $2 \%$ during the third year and less than $1 \%$ during the fifth year. Thus if a biological father was absent from the child's home at birth he is likely to enter the child's household very early in the child's life or not at all. The rate at which biological fathers move out is about $6 \%$ in the first year of life for children of black mothers, versus about 3\% for children of white and Hispanic mothers. The exit rate drops with age for all groups, more rapidly for blacks, but convergence is quite slow. The monotonic decline in the rate of exit of the biological father as a child ages contrasts with the typical pattern of the hazard of divorce, which increases with marriage duration in the first year of marriage before declining (see Waite and Lillard, 1991, for example). Note that the simulations on which the figures are based do not hold constant marital duration, the mother's age, the number of siblings, and other factors that may affect the risk of exit of the biological father. Again, we are not aware of any comparable estimates in the literature.

Figure 3a shows the cumulative duration of time spent with a stepfather. Race and ethnic differences are negligible in this case: by age 18, the expected duration of time spent with a stepfather is about four years for all groups. Figure $3 \mathrm{~b}$ shows the patterns conditional on the mother being single at the time the child was born. A somewhat more noticeable racial gap appears in this case: children of white and Hispanic mothers who were single at birth accumulate about 6 years with a stepfather by age 18, compared to fewer than 5 years for children of black mothers. The underlying annualized transition rates shown in Figure 4 indicate that the annual rate of gaining a stepfather rises with age until the teenage years, and is persistently highest for 
children of black mothers, followed by Hispanics and whites. The exit rate of stepfathers rises with age until about age 5 (8 for whites), and is higher for blacks than for the other groups. This suggests that step families are less stable for blacks than for whites, with Hispanics in between. The greater instability for blacks is masked in the cumulative averages in Figure 3 because blacks experience both greater entry and greater exit of stepfathers than whites and Hispanics.

Figure 5 summarizes annual transition rates of children among union states. Many studies have presented such estimates for adults, but they have rarely been presented for children, and never for the full set of transitions shown here. The annual entry rate to cohabitation is about $3 \%$ for children of black mothers during the preschool years, compared to 6-7\% for children of white and Hispanic mothers. The cohabitation entry rate rises with age until 15, and the racial gap is stable until about age 13. The transition rate from single to married is highest for children of white mothers in the first year of life at $9 \%$, declines to $4 \%$ by age 5 , and then rises gradually to $7 \%$ by age 12 . The pattern for children of black and Hispanic mothers is similar but at lower levels. The rate at which cohabitations are converted to marriage is relatively constant during the preschool ages at $16-19 \%$ per year for whites, $14-15 \%$ for blacks, and $11-12 \%$ for Hispanics. The conversion rate rises steadily during the school years, and blacks catch up to whites by age 10. The rate at which cohabitations dissolve is about $10 \%$ per year for blacks through age 9 , and declining thereafter. The rates for whites and Hispanics are around $8 \%$ at age 1 and decline slowly with age. Finally, the annual divorce rate is $5 \%$ for blacks through age 7 , then declining steadily to about $1 \%$ by age 18 . The divorce rate for whites and Hispanics is about $3 \%$ through age 8 , then declining steadily to $1 \%$ at age 18 . 


\section{DISCUSSION}

The most striking finding of the analysis is that children of black mothers spend far less time living with their biological father and mother together than do children of white and Hispanic mothers. This pattern is well known, but has never been documented as explicitly and thoroughly as we have done here. The two most important proximate demographic determinants of this large racial gap are the much higher propensity of black women to conceive children outside of a union, and the lower rate of "shotgun" unions for blacks compared to whites. If black women conceived children outside of a union at the same rate as white women, and all other black-white differences in behavior remained the same, the black-white difference in the percent of childhood spent with the biological father would be $35 \%$ smaller. ${ }^{24}$ If black women entered shotgun unions while single and pregnant at the same rate as whites, other things equal, the gap would be $38 \%$ smaller. ${ }^{25}$ If both sets of black-white differences were eliminated, the gap would be 57\% smaller. Other black-white differences in demographic behavior have much smaller effects; for example, the higher rate of divorce and exit from cohabitations among blacks accounts for only $17 \%$ of the gap. ${ }^{26}$

\footnotetext{
${ }^{24}$ The calculations underlying this result are based on all simulated children, including those who were observed for less than 18 years. The simulated percent of childhood with the biological father present is $72.8 \%$ for whites and 34.1\% for blacks, a difference of 38.7 percentage points. When the simulation is re-computed setting the black intercept coefficients for conceiving a child outside of a union to zero (event 2 in state 1 and events 1 and 2 in state 2), the simulated percent for blacks increases to $47.6 \%$. The resulting white-black gap is 25.2 percentage points, a decline of 13.5 percentage points, or $35 \%$ of the original 38.7 percentage point gap.

${ }^{25}$ This simulation sets the black coefficients to zero for events 4 and 6 in state 5 and events 5 and 7 in state 6 (entering a union with the father of the to-be born child).

${ }^{26}$ This simulation sets the black coefficients (including interactions) to zero for event 3 (ending a union) in states $3,4,7$, and 8.
} 
An important question is what explains the underlying black-white differences in demographic behavior that lead to the observed gap in time spent living with the biological father. Our analysis is descriptive, so we cannot provide any definitive answers here. We can, however, examine whether the differences can be accounted for by differences in the family background and other characteristics of black and white women. Family background characteristics were not included in the specification because of the large number of additional parameters that would be required (21 per additional variable). However, with a simpler estimation approach, it is possible to include family background variables. In this approach we estimate eight multinomial logit models independently, one for each state, without accounting for unobserved heterogeneity or integrating over alternative possible sequences of events and spell beginning and ending dates. The simulated share of childhood spent with the biological father based on this approach is very similar to the share based on the more complex estimation approach. This gives us some confidence that this simpler approach will provide a reasonable indication of the importance of family background variables. Using this approach, we added to all of the logit models a set of categorical indicators for the family structure the woman herself experienced at age $14^{27}$; a dummy variable for immigrants; education of the woman's mother and father (with dummies for missing values and the missing cases set to zero); and the woman's number of siblings. There are large differences on average between whites and blacks in many of these variables. For example, $79 \%$ of white women lived with both biological parents at age 14 , compared to $50 \%$ of black women. Parental education is higher by two years for fathers and one

${ }^{27}$ The categories are lived with (1) biological mother and biological father; (2) biological mother and another man; (3) biological mother and no man; (4) another woman and biological father; (5) no woman and biological father; and (6) any other living arrangement. 
year for mothers, and black women have 4.7 siblings compared to 3.1 for whites. Based on these estimates, we find that if black and white women had the same mean background characteristics, the black-white difference in the percent of childhood spent with both biological parents would be $13-17 \%$ smaller (depending on whether the black or white means are used). Thus, we conclude that differences in family background matter, but they are not a major factor in accounting for the black-white gap in time spent with the biological father.

We also examined the role of two other key variables, the woman's education and cognitive achievement, the latter measured by the percentile score on the Armed Forces Qualification Test (AFQT). We do not model the processes that determine these two variables, and we do not claim to estimate the causal impact of education and cognitive ability on demographic behavior. This exercise should be viewed simply as an attempt to determine how much of the black-white gap in residence with the biological father can be "accounted for" by these two important observable characteristics of women. As in the case of family background, the black-white difference in the mean AFQT score is substantial: 53.0 for whites versus 22.8 for blacks. However, blacks and whites are much closer on mean completed years of education: 13.7 for whites versus 13.1 for blacks. The estimates show that education is a highly significant determinant of all of the demographic behaviors, but the black-white education gap accounts for only 5-7\% of the biological father co-residence gap, conditional on equalized family background. Conditional on equalized family background and education, the AFQT gap accounts for $19-50 \%$ of the remaining gap, depending on which means are used. This leaves some ambiguity about how much of the gap can be explained by cognitive ability, but it suggests that cognitive achievement may be an important source of the gap. 
These results should be interpreted carefully. Our analysis reveals a large difference in the time spent with the biological father for children of black and white mothers, and the analysis identifies the main differences in the proximate demographic behaviors that give rise to the racial gap. The analysis also suggests that black-white differences in observable family background characteristics and education of women are not the main explanations for the different family experiences of black and white children. However, the analysis has not identified the main causal factors that do determine the gap. For example, we do not know the importance of poor economic prospects of potential mates, cultural attitudes, psychological factors, or other factors. Equally important, the consequences of racial differences in family structure experiences for child development and subsequent outcomes are not addressed by this analysis. It could turn out, for example, that absence of the biological father from the household of children of black mothers is on average less harmful to child development than is the case for children of white mothers. ${ }^{28}$

Another finding of interest concerns the cohabitation experiences of children. Given the large increase in cohabitation, this issue has received a lot of attention recently. Brown (2004) finds that children living in biological-cohabiting-parent families experience worse outcomes than children residing with married biological parents. Raley and Wildsmith (2004) argue that ignoring cohabitation biases estimates of family instability experienced by children. Our estimates imply that cohabitation accounts for $2.6 \%$ of the time spent living with both biological parents during childhood for whites, $16.8 \%$ for blacks, and $7.2 \%$ for Hispanics. Thus, despite the

\footnotetext{
${ }^{28}$ However, Aughinbaugh et al. (2005, p. 465) report that divorce and remarriage have larger negative effects on reading achievement of black children than for white and Hispanic children.
} 
relatively high incidence of cohabitation (see Table 2), it accounts for a negligible share of time spent with both biological parents, except for the children of black mothers.

The last main finding worth emphasizing is the relatively modest role of stepfathers in the family structure experiences of children. Of all time spent living with the biological mother and a father figure, simulations show that stepfathers account for $15 \%, 44 \%$, and $22 \%$ for children of white, black, and Hispanic mothers, respectively. The large share for blacks is not a result of a large absolute share of childhood spent with a stepfather: on average $17 \%$ of childhood is spent with a stepfather by children of black mothers, compared to $10 \%$ for whites and $12 \%$ for Hispanics. Rather, only $34 \%$ of childhood is spent with the biological father by children of black mothers, so stepfathers loom relatively large by comparison.

\section{CONCLUSIONS}

This is the first study of demographic behavior that is designed to show directly how union formation, dissolution, and childbearing interact to determine the family structure experiences of children. The rich analytical approach incorporates all of the key behaviors that influence the dynamics of family structure experiences, including the choice between "current" and "new" men. The NLSY79 event history data are exploited more fully than in previous studies as well, yielding an in-depth characterization of family structure dynamics. Limitations of the data are addressed by an innovative statistical approach that extracts the maximum amount of useful information from the data with as few auxiliary assumptions as possible.

There are some important limitations to the analysis, in addition to those already discussed. The results are restricted to one cohort of women, and this cohort has not yet 
completed its union formation and dissolution behavior The childbearing of the cohort is close to complete, but we cannot extrapolate from the results to infer how the family structure experiences of children born to mothers at relatively old ages will be influenced by union formation and dissolution behavior beyond age 45 . The choice of whether a child lives with the biological mother is not modeled. It is worth emphasizing again that all of the simulation results presented in the paper are conditional on children living with their biological mother for their entire childhood. In fact, most children spend most or all of their childhood with their biological mother, but accounting for time spent by children away from the biological mother would provide a more complete picture of family structure experiences. The same is true for other aspects of family structure, such as the presence of grandparents in the child's household. Pregnancies that do not result in a live birth are not modeled.. Finally, characteristics of men and children (other than number and ages) are not considered in the analysis. We did investigate whether the sex composition of children affected any of the demographic behaviors, but there was no evidence of such effects. It would be quite interesting to extend the analysis to incorporate the choice among "types" of men; for example low versus high education, low versus high income. It would also be useful to explicitly model temporary separations and reconciliations, since these could affect children.

In ongoing research, we focus on two extensions of the analysis. The first is to model the effects of economic and marriage market conditions and government policies that affect union formation, dissolution, childbearing, and “choice of man" incentives, such as welfare reform, child support enforcement, and the Earned Income Tax Credit. The second is to integrate the type of analysis conducted here with an analysis of the effects of family structure on child outcomes. 


\section{References}

Andersson, G. 2002. “Children’s Experience of Family Disruption and Family Formation: Evidence from 16 FFS Countries.” Demographic Research 7: 343-363 (online journal: http://www.demographic-research.org)..

Aquilino, W. 1996. "The Life Course of Children Born to Unmarried Mothers: Childhood Living Arrangements and Young Adult Outcomes.” Journal of Marriage and the Family 58 (May): 293-310.

Aughinbaugh, A., C. Pierret, and D. Rothstein. 2005. “The Impact of Family Structure Transitions on Youth Achievement: Evidence from the Children of the NLSY79.” Demography 42 (3): 447-468.

Bennet, N., D. Bloom, and C. Miller. 1995. “The Influence of Nonmarital Childbearing on the Formation of First Marriages. “ Demography 32: 47-62.

Brien, M., L. Lillard, and L. Waite. 1999. “Interrelated Family-Building Behaviors:

Cohabitation, Marriage, and Non-Marital Conception.” Demography 36 (4): 535-52.

Brown, S.L. 2004. "Family Structure and Child Well-Being: The Significance of Parental Cohabitation.” Journal of Marriage and the Family 66 (2): 351-367.

Bumpass, L., and H. Lu. 2000. "Trends in Cohabitation and Implications for Children’s Family Contexts in the United States.” Population Studies 54: 29-41.

Bumpass, L. J. Sweet, and A. Cherlin. 1991. "The Role of Cohabitation in Declining Rates of Marriage.” Journal of Marriage and the Family 53 (Nov.): 913-27.

Bumpass, L., R.K. Raley, and J.A. Sweet. 1995. "The Changing Character of Stepfamilies: Implications of Cohabitation and Nonmarital Childbearing.” Demography 32 (3): 425-436.

Carlson, M., S. McLanahan, and P. England. 2004. "Union Formation in Fragile Families.” Demography 41 (2): 237-62.

Chase-Lansdale, P.L., A. Cherlin, and K. Kiernan. 1995. "The Long-Term Effects of Parental Divorce on the Mental health of Young Adults: A Developmental Perspective.” Child Development 66: 1614-34.

Cherlin, A. 1999. “Going to Extremes: Family Structure, Children’s Well-Being, and Social Science.” Demography 36 (4): 421-8.

Fields, J. And L. Casper. 2001. “America’s Families and Living Arrangements.” U.S. Census Bureau, Current Population Reports P20-537, June. 
Gennetian, L.A. (2005). "One or Two Parents? Half or Step Siblings? The Effect of Family Structure on Young Children’s Achievement.” Journal of Population Economics 18: 415-436.

Ginther, D. K., and R. A. Pollak. 2004. “Family Structure and Children’s Educational Outcomes.” Demography 41 (4): 671-96.

Graefe, D., and D. Lichter. 1999. "Life Course Transitions of American Children.” Demography 36 (2): 205-18.

Hetherington, M. and M. Stanley-Hagan. 1999. "The Adjustment of Children with Divorced Parents: A Risk and Resiliency Perspective.” Journal of Child Psychology and Psychiatry 40 (1): 129-140.

Heuveline, P., J.M. Timberlake, and F.F. Furstenberg. 2003. "Sifting Childrearing to Single Mothers: Results from 17 Western Countries.” Population and Development Review 29 (1): 4771.

Hofferth, S.L. (2006). “Residential Father Family Type and Child Well-being: Investment Versus Selection.” Demography 43 (1): 53-78.

Hughes, M.E., and L. J. Waite. 2007. “The Aging of the Second Demographic Transition,” in Social Structures: The Impact of Demographic Changes on the Well-being of Older Persons, edited by W. Schaie and P. Uhlenberg. New York: Springer, in press.

Krieder, R., and J. Fields. 2002. “Number, Timing, and Duration of Marriages and Divorces:1996.” U.S. Census Bureau, Current Population Reports P70-80, Feb.

Lang, K., and J. Zagorsky. 2001. “Does Growing Up With A Parent Absent Really Hurt?” Journal of Human Resources 36 (2): 253-73.

Lillard, L. A. 1993. "Simultaneous Equations for Hazards,” Journal of Econometrics 56: 189217.

Manning, W.D. 2004. “Children and the Stability of Cohabiting Couples.” Journal of Marriage and the Family 66 (August): 674-689.

Manning, W.D., P.J. Smock, and D. Majumdar. 2004. “The Relative Stability of Cohabiting and Marital Unions for Children.” Population Research and Policy Review 23: 135-159.

Martin, J., B. Hamilton, S. Ventura, F. Menaker, and M. Park. 2002. "Births: Final Data for 2000.” National Center for Health Statistics, National Vital Statistics Reports, 50 (6), Feb. 12.

McLanahan, S., and G. Sandefur. 1994. Growing Up With A Single Parent. Cambridge: Harvard 
University Press.

Moffitt, R.A., and M.S. Rendall. 1995. "Cohort Trends in the Lifetime Distribution of Female Family Headship in the U.S., 1968-1985.” Demography 32 (3): 407-424.

Raley, R.K. 2001. "Increasing Fertility in Cohabiting Unions: Evidence for the Second Demographic Transition in the United States?” Demography 38 (1): 59-66.

Raley, R.K., and E. Wildsmith. 2004. “Cohabitation and Children’s Family Instability.” Journal of Marriage and the Family 66 (1): 210-219.

Sigle-Rushton, W., J. Hobcroft, and K. Kiernan. 2005. "Parental Divorce and Subsequent Disadvantage: A Cross-Cohort Comparison.” Demography 42 (3): 427-446.

Upchurch, D., L. Lillard, and C. Panis. 2001. “The Impact of Nonmarital Childbearing On Subsequent Marital Formation and Dissolution.” in Out of Wedlock: Causes and Consequences of Nonmarital Fertility, edited by L. Wu and B. Wolfe, New York: The Russell Sage Foundation.

Waite, L., and L. Lillard. 1991. “Children and Marital Disruption.” American Journal of Sociology 96 (4): 930-53. 
Table 1: Definition of states and events

\begin{tabular}{|l|l|l|l|l|l|}
\hline State & $\begin{array}{l}\text { Preg- } \\
\text { nant }\end{array}$ & $\begin{array}{l}\text { Marital } \\
\text { status }\end{array}$ & $B_{t}$ & $N_{t}$ & Events for which the woman is at risk \\
\hline 1 & no & single & 0 & NA & $\begin{array}{l}\text { 2. Conceive with new man. } \\
\text { 5. Cohabit with new man. } \\
\text { 7. Marry new man }\end{array}$ \\
\hline 2 & no & single & $>0$ & NA & $\begin{array}{l}\text { 1. Conceive with current man. } \\
\text { 2. Conceive with new man. } \\
\text { 4. Cohabit with current man. } \\
\text { 5. Cohabit with new man. } \\
\text { 6. Marry current man } \\
\text { 7. Marry new man }\end{array}$ \\
\hline 3 & no & cohabiting & NA & NA & $\begin{array}{l}\text { 1. Conceive with current man. } \\
\text { 3. Become single. } \\
\text { 6. Marry current man }\end{array}$ \\
\hline 4 & no & married & NA & NA & $\begin{array}{l}\text { 1. Conceive with current man. } \\
\text { 3. Become single. }\end{array}$ \\
\hline 5 & yes & single & $>0$ & 0 (current) & $\begin{array}{l}\text { 4. Cohabit with current man. } \\
\text { 6. Marry current man }\end{array}$ \\
\hline 6 & yes & single & 0 or $>0$ & 1 (new) & $\begin{array}{l}\text { 5. Cohabit with new man. } \\
\text { 7. Marry new man }\end{array}$ \\
\hline 7 & yes & cohabiting & NA & NA & $\begin{array}{l}\text { 3. Become single. } \\
\text { 6. Marry current man }\end{array}$ \\
\hline 8 & yes & married & NA & NA & \begin{tabular}{l} 
3. Become single \\
\hline
\end{tabular} \\
\hline
\end{tabular}

Notes: NA indicates Not Applicable.

$B_{t}$ is the number of children born since the end of the previous union.

$N_{t}=0$ if the current pregnancy, if any, is with the current man, and $N_{t}=1$ if it is with a new man. The numbering of events corresponds with the order in which they are listed in the text. In state 6 , the "new" man is the man with whom she conceived the current pregnancy. This man became the current man at the time of the conception, but we refer to him as the new man to avoid confusion. 
Table 2: Characteristics of Sample Women

\begin{tabular}{|c|c|c|c|}
\hline & White & Black & Hispanic \\
\hline Ever married & 88.6 & 61.2 & 80.7 \\
\hline Ever ended marriage conditional on ever married & 37.2 & 52.3 & 42.1 \\
\hline $\begin{array}{l}\text { Ever ended marriage conditional on kids present and ever } \\
\text { married }\end{array}$ & 25.4 & 41.7 & 31.9 \\
\hline $\begin{array}{l}\text { Ever married more than once conditional on experiencing } \\
\text { end of first marriage }\end{array}$ & 60.5 & 30.0 & 49.3 \\
\hline Ever cohabited & 42.2 & 34.6 & 37.3 \\
\hline Ever move from cohabitation to marriage & 34.7 & 21.2 & 24.8 \\
\hline Percent of cohabitation spells that end in marriage & 74.5 & 59.1 & 64.3 \\
\hline $\begin{array}{l}\text { Percent of cohabitation spells that end in marriage, } \\
\text { conditional on a child being born during cohabitation }\end{array}$ & 60.0 & 56.2 & 43.4 \\
\hline Number of children ever born $=0$ & 21.7 & 18.2 & 16.9 \\
\hline Mean number of children ever born & 1.69 & 1.87 & 1.98 \\
\hline Ever conceive a child while single & 21.7 & 63.9 & 37.4 \\
\hline Ever give birth while single & 10.7 & 58.4 & 26.0 \\
\hline Ever conceive a child while cohabiting & 6.8 & 7.3 & 8.9 \\
\hline Ever give birth while cohabiting & 4.0 & 7.6 & 7.9 \\
\hline Ever conceive a child while married & 67.9 & 34.5 & 63.5 \\
\hline Ever give birth while married & 71.5 & 38.0 & 65.9 \\
\hline Ever had children living with no man (if ever had kids) & 36.5 & 82.3 & 52.4 \\
\hline Ever had children without biol father (if ever had kids) & 38.4 & 82.5 & 53.0 \\
\hline Ever had children with a stepfather present (if ever had kids) & 24.2 & 35.6 & 29.5 \\
\hline Mean age at first birth & 25.1 & 21.7 & 23.2 \\
\hline \multicolumn{4}{|l|}{ Marital status at first birth: } \\
\hline single & 11.4 & 66.6 & 25.9 \\
\hline cohabiting & 3.2 & 4.0 & 5.6 \\
\hline Married & 85.3 & 29.4 & 68.6 \\
\hline Mean age at last observation & 39.0 & 38.4 & 38.1 \\
\hline Sample size & 2,286 & 1,340 & 854 \\
\hline
\end{tabular}

Notes: All entries are sample means (multiplied by 100 for binary variables). Observations are weighted by the inverse of the number of distinct event histories per woman. See the text for description of how multiple event histories are generated. Only conceptions resulting in a live birth are included here. In cases in which the date of an event is uncertain, the earliest possible date is used to compute the statistics. However, this has very little impact on the statistics; we re-computed the statistics using the latest possible date, and they were always within two percentage points of the statistics shown in the table, and usually were identical. 
Table 3: Family Structure Experiences of Sample Children in the First 18 years

\begin{tabular}{|c|c|c|c|}
\hline & White & Black & Hispanic \\
\hline \multicolumn{4}{|l|}{ Mother' marital status at conception: } \\
\hline Single & 15.7 & 63.9 & 27.5 \\
\hline Cohabiting & 4.6 & 5.2 & 5.8 \\
\hline Married & 79.8 & 31.0 & 66.7 \\
\hline \multicolumn{4}{|l|}{ Mother's marital status at birth: } \\
\hline Single & 8.2 & 58.8 & 20.2 \\
\hline Cohabiting & 2.8 & 5.3 & 5.6 \\
\hline Married & 88.9 & 36.0 & 74.2 \\
\hline Conceived while single: percent born in cohabitation & 5.7 & 2.4 & 6.1 \\
\hline Conceived while single: percent born in marriage & 46.5 & 7.8 & 25.2 \\
\hline Conceived in cohabitation: percent born in marriage & 54.4 & 21.3 & 28.1 \\
\hline Ever lived with no father & 30.1 & 75.7 & 43.3 \\
\hline Percent of time with no father if $>0$ & 38.1 & 65.0 & 46.8 \\
\hline Percent of time with no biological father if $>0$ & 58.9 & 75.7 & 66.2 \\
\hline Ever live with stepfather & 17.1 & 26.8 & 22.6 \\
\hline Percent of time with stepfather if $>0$ & 38.9 & 31.6 & 38.9 \\
\hline Ever live with biological father & 94.0 & 51.6 & 84.7 \\
\hline Percent of time with biological father if $>0$ & 82.9 & 66.8 & 78.1 \\
\hline Ever lived with cohabiting father & 13.5 & 25.9 & 22.3 \\
\hline Percent of time lived with cohabiting father (if $>0$ ) & 19.0 & 19.1 & 26.4 \\
\hline Biological father ever moved in (if not present at birth) & 27.4 & 17.8 & 23.6 \\
\hline Biological father ever moved out (if ever present) & 24.3 & 43.3 & 29.4 \\
\hline Step father ever moved in (if biological father ever not present) & 52.6 & 34.9 & 50.3 \\
\hline Step father ever moved out (if ever present) & 36.5 & 51.2 & 36.8 \\
\hline Mean age at last observation & 12.7 & 14.7 & 13.3 \\
\hline Sample size & 3,818 & 2,479 & 1,673 \\
\hline
\end{tabular}

Note: Unit of analysis is a child. See notes to Table 2. 
Table 4: Simulated Distribution of Lifetime Years Spent with Biological Father

\begin{tabular}{|l|l|l|l|}
\hline Percentile & \multicolumn{1}{|c|}{ White } & \multicolumn{1}{c|}{ Black } & Hispanic \\
\hline 10 & 0.9 & 0 & 0 \\
\hline 25 & 4.2 & 0 & 2.4 \\
\hline 50 & 8.8 & 1.2 & 7.8 \\
\hline 75 & 13.5 & 7.7 & 13.2 \\
\hline 90 & 17.0 & 13.9 & 16.9 \\
\hline Mean & $8.9(72.8 \%)$ & $4.3(34.1 \%)$ & $8.1(64.1 \%)$ \\
\hline Percent zero & 6.2 & 43.8 & 14.5 \\
\hline
\end{tabular}

Note: The simulation runs through age 18 or the last observed age, whichever is less. The figures in parentheses next to the means are the mean percent of all observed simulated childhood years spent with the biological father and mother, accounting for the fact that many children are observed for less than 18 years. 


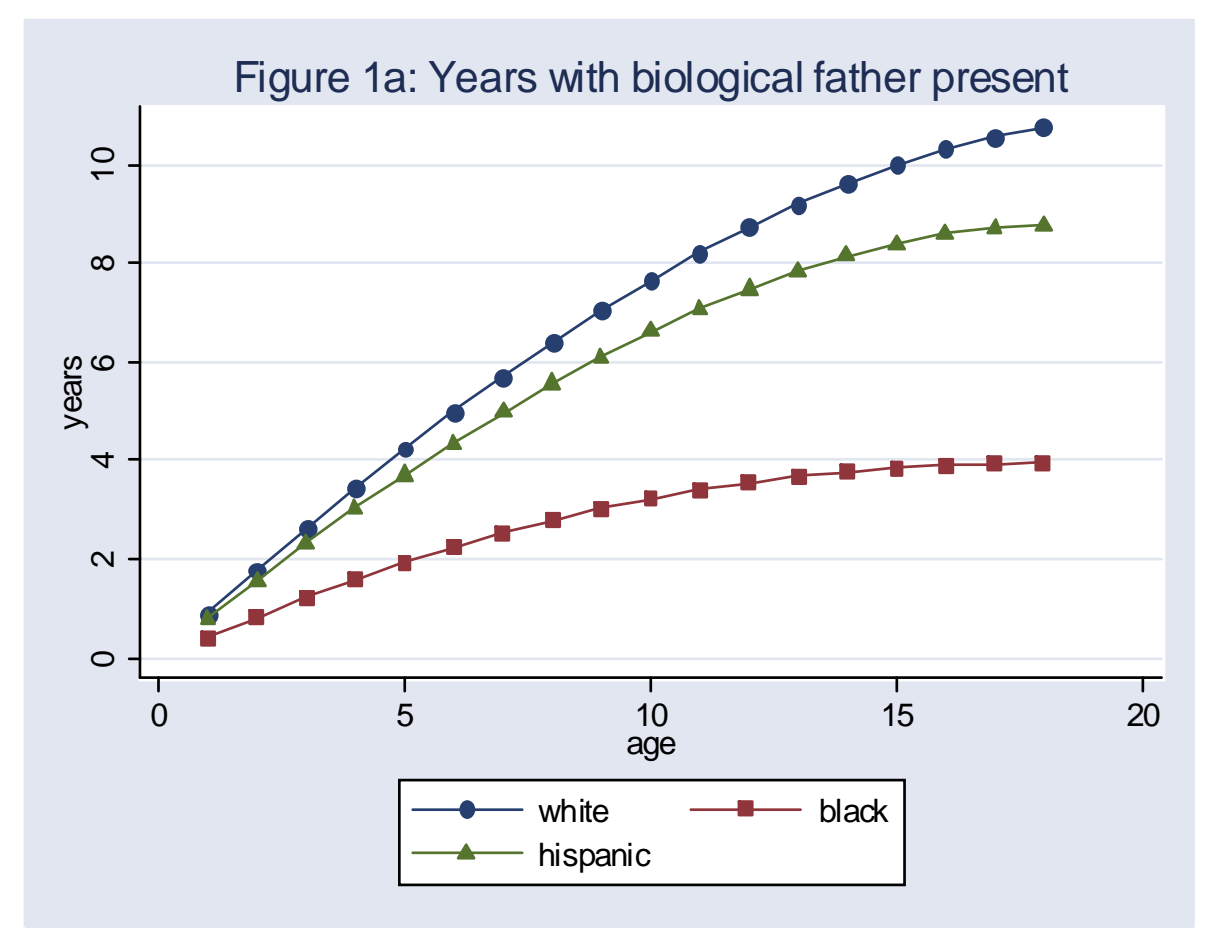

Figure 1c: Years with biological father present: cohabiting at birth

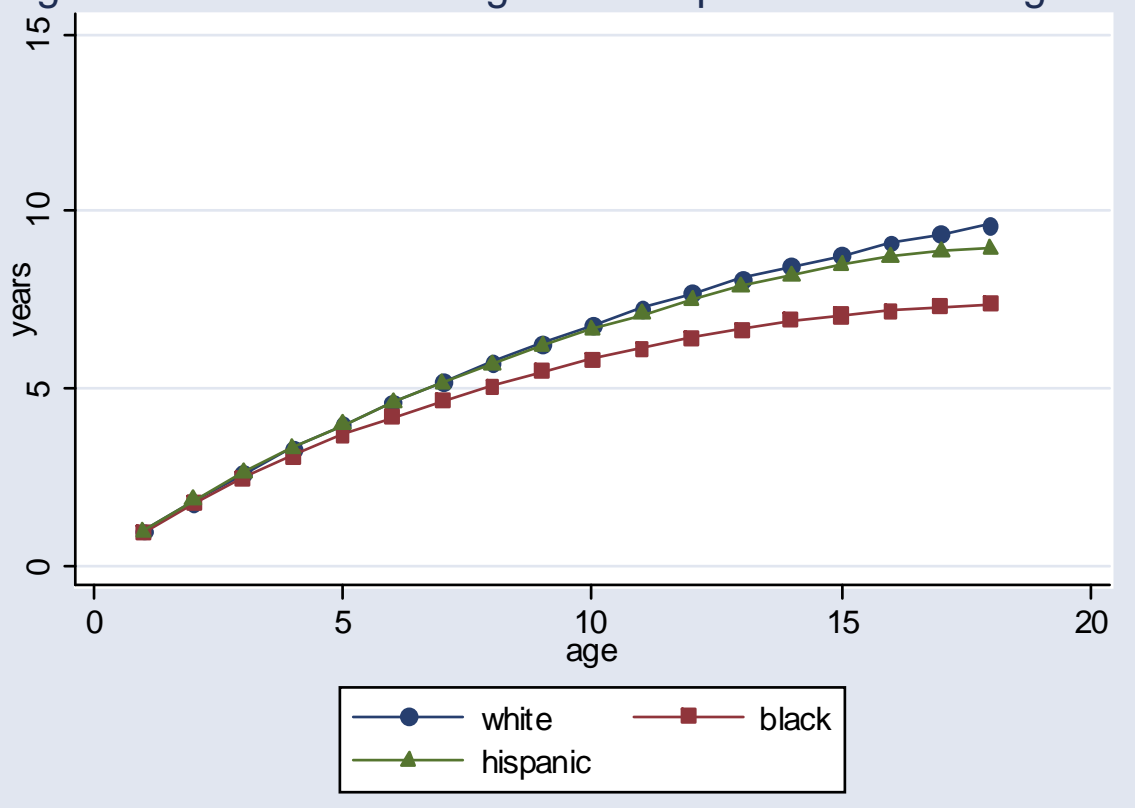

Figure 1b: Years with biological father present: single at birth

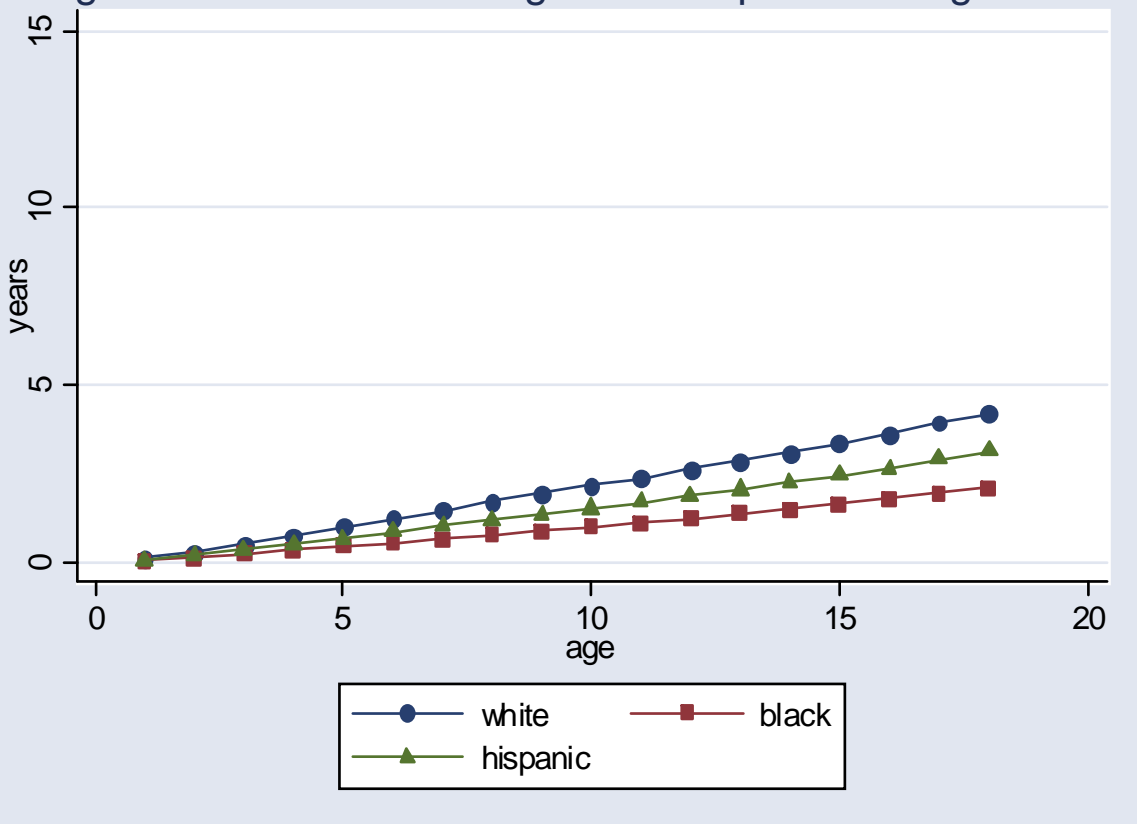

Figure 1d: Years with biological father present: married at birth

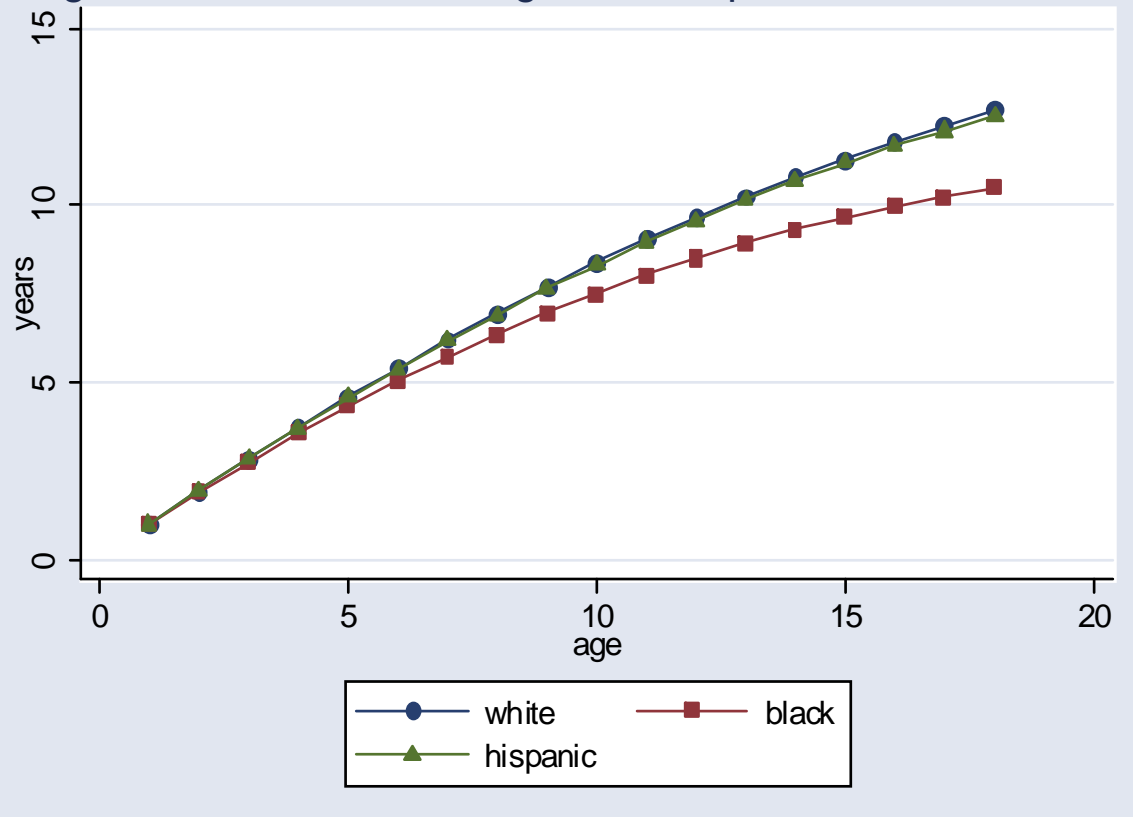


Figure 1e: Years with biological father present: single at conception

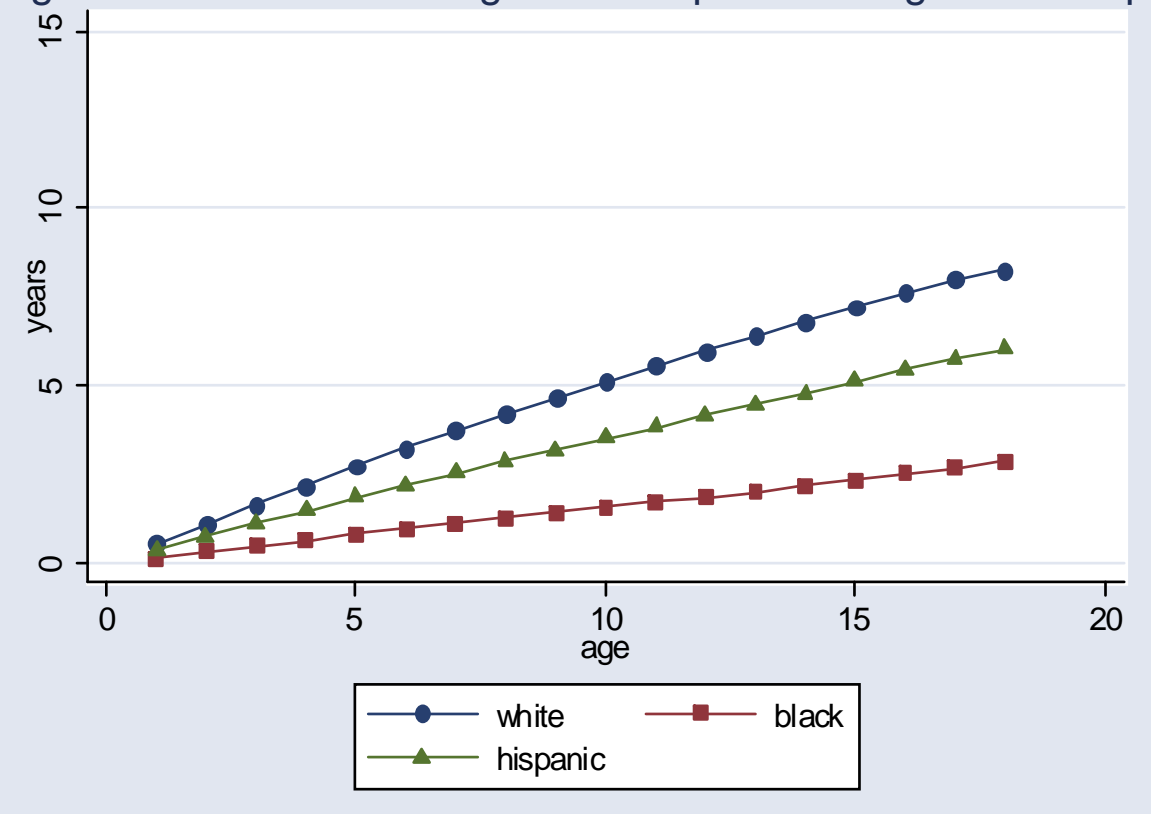

Figure 1g: Years with biological father present: married at conception

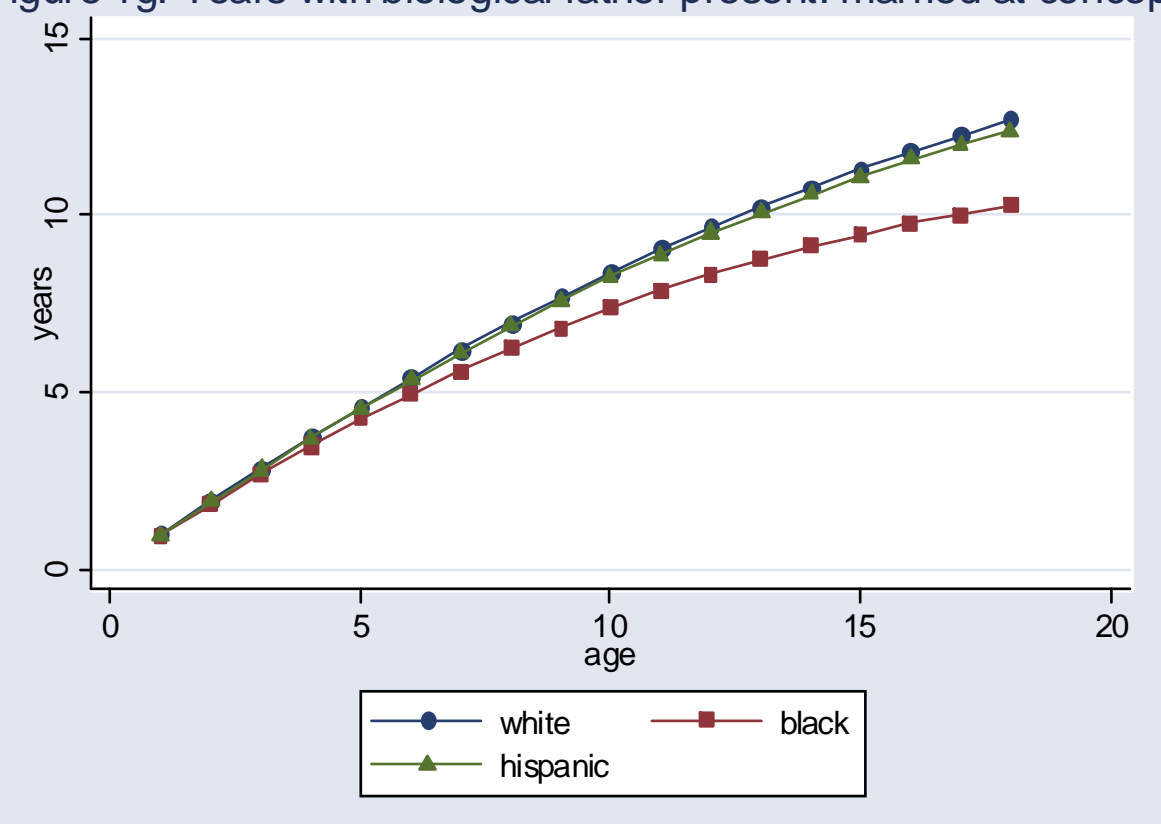

Figure 1f: Years with biological father present: cohabiting at conception

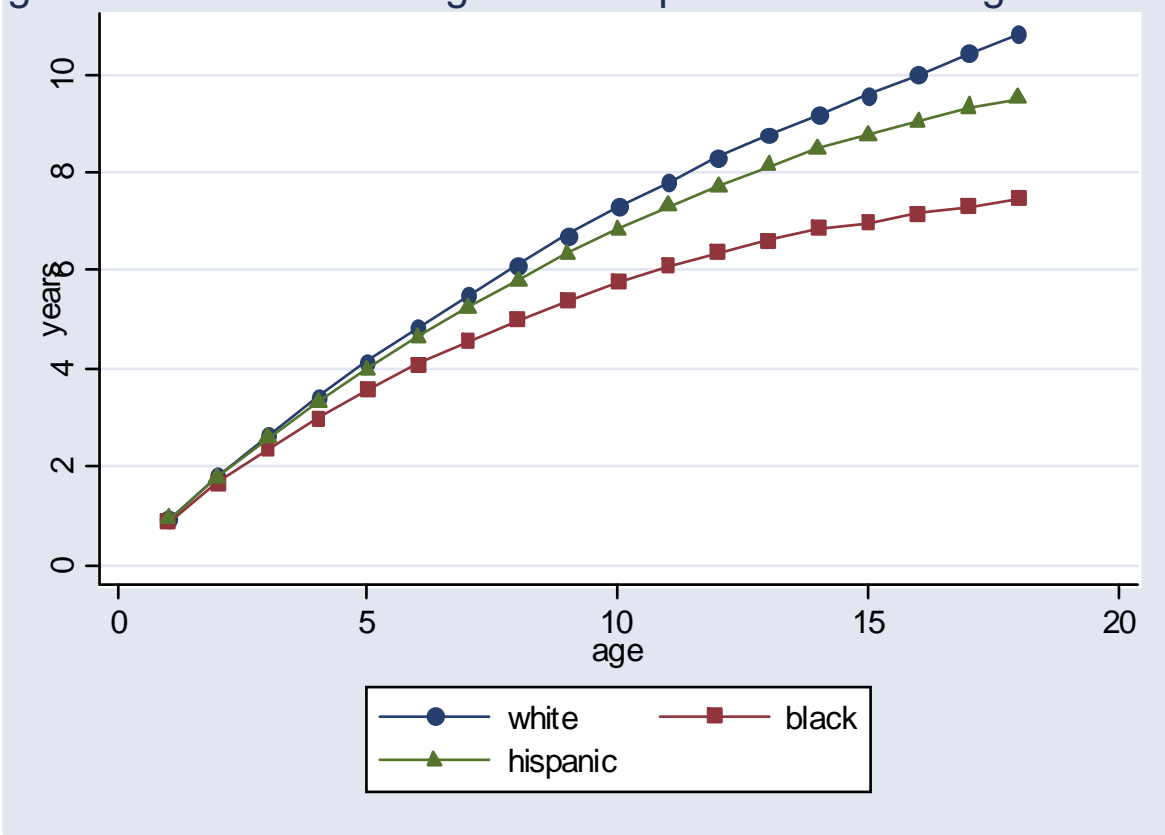



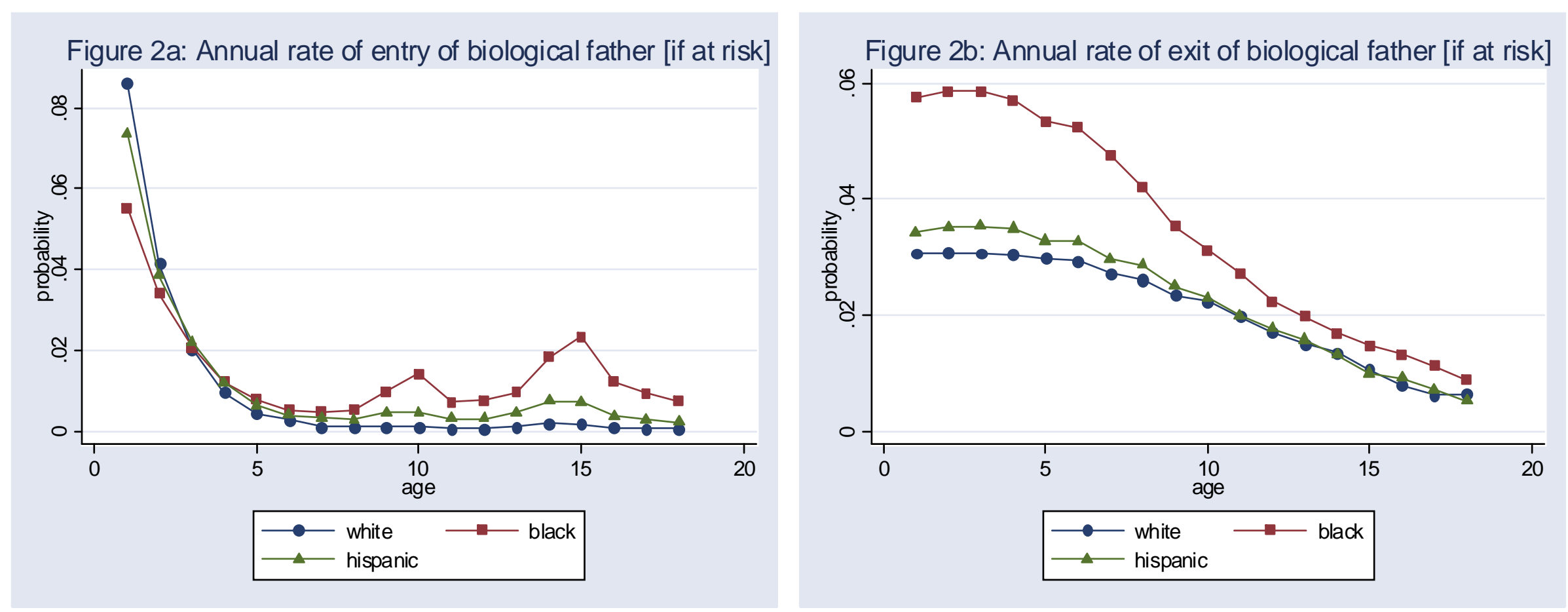

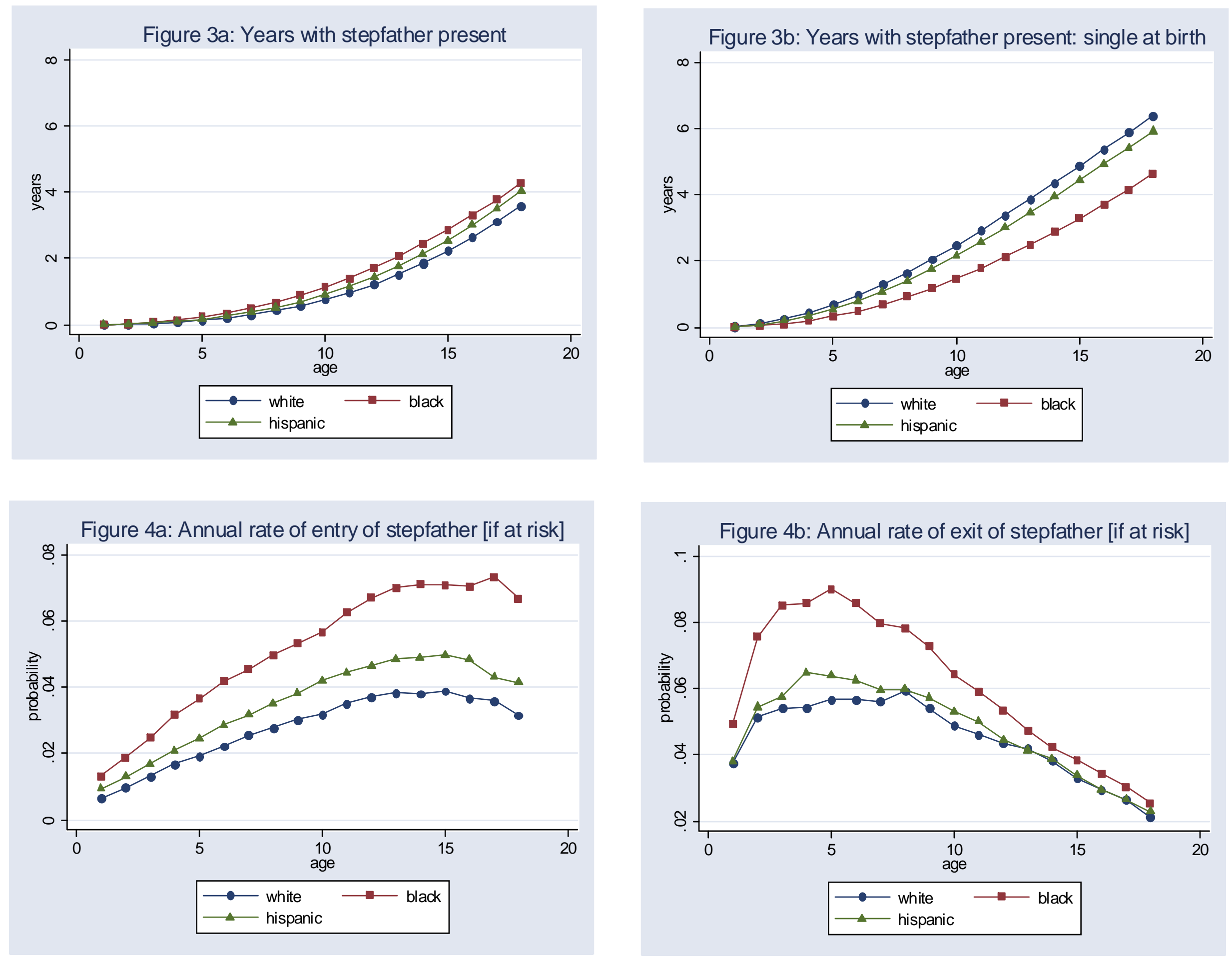
Figure 5a: Annual transition rate: single to cohabiting [if at risk]

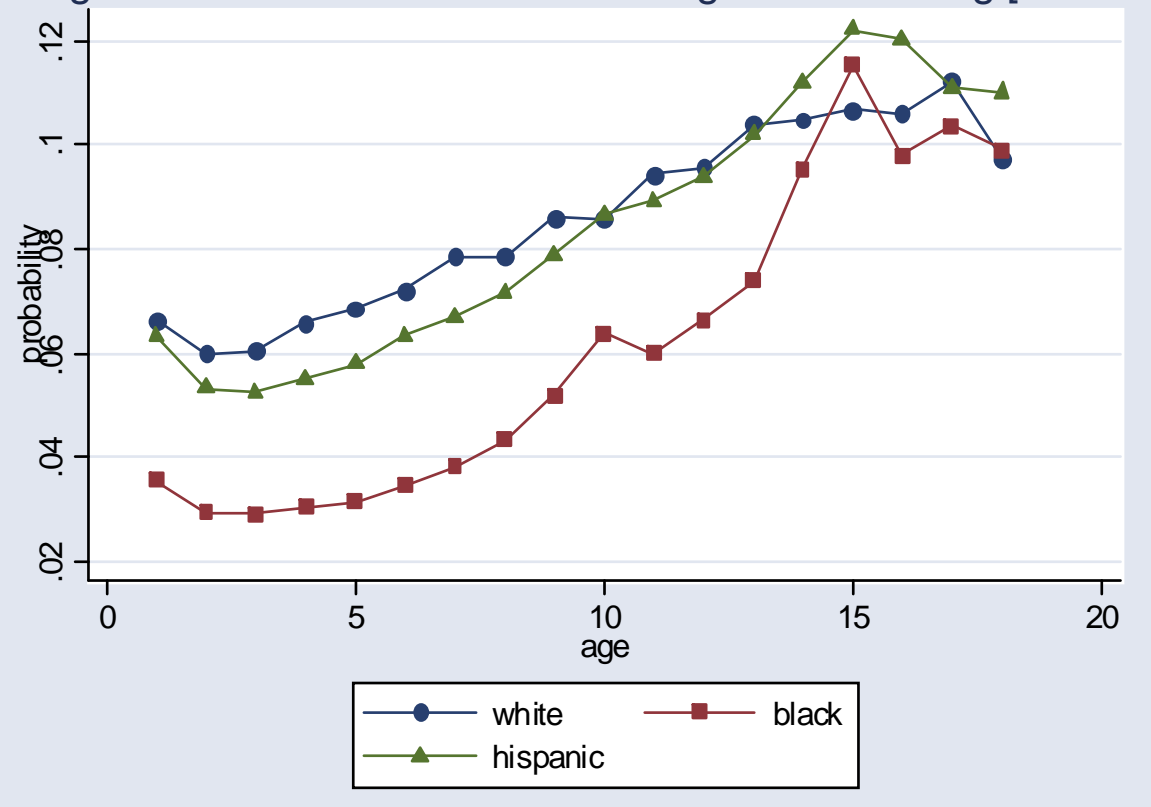

Figure 5c: Annual transition rate: cohabiting to married [if at risk]

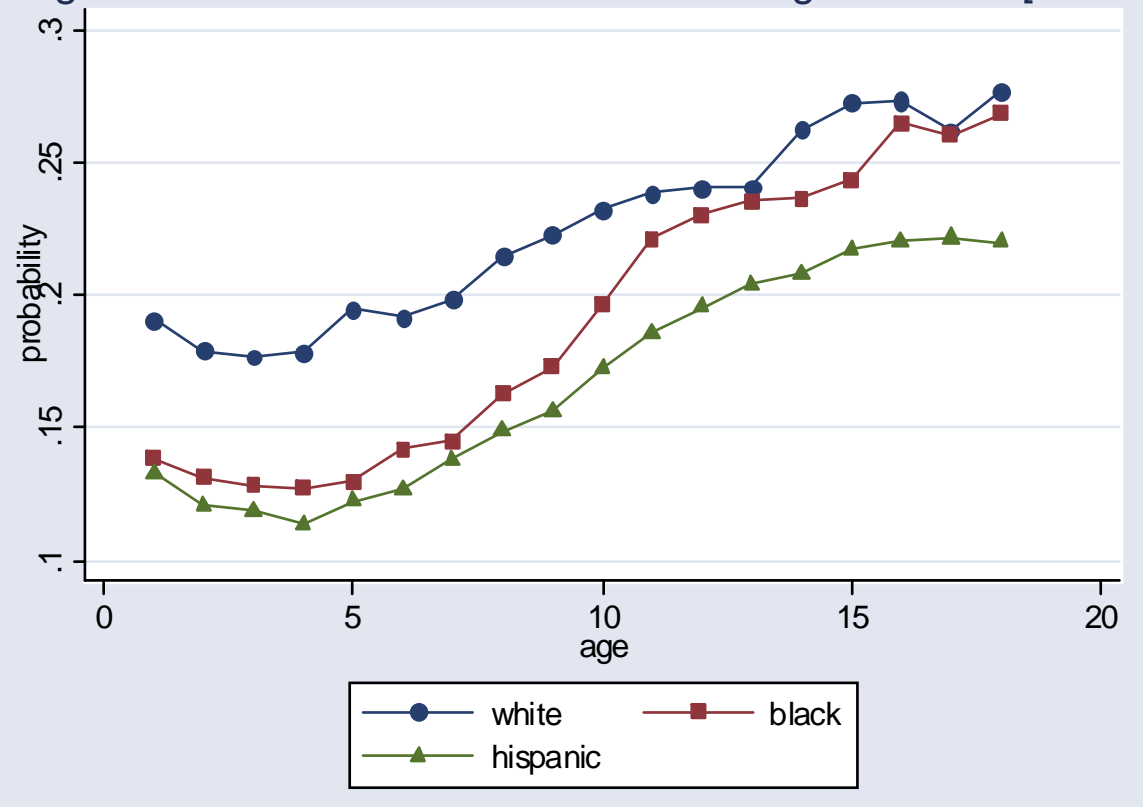

Figure 5b: Annual transition rate: single to married [if at risk]

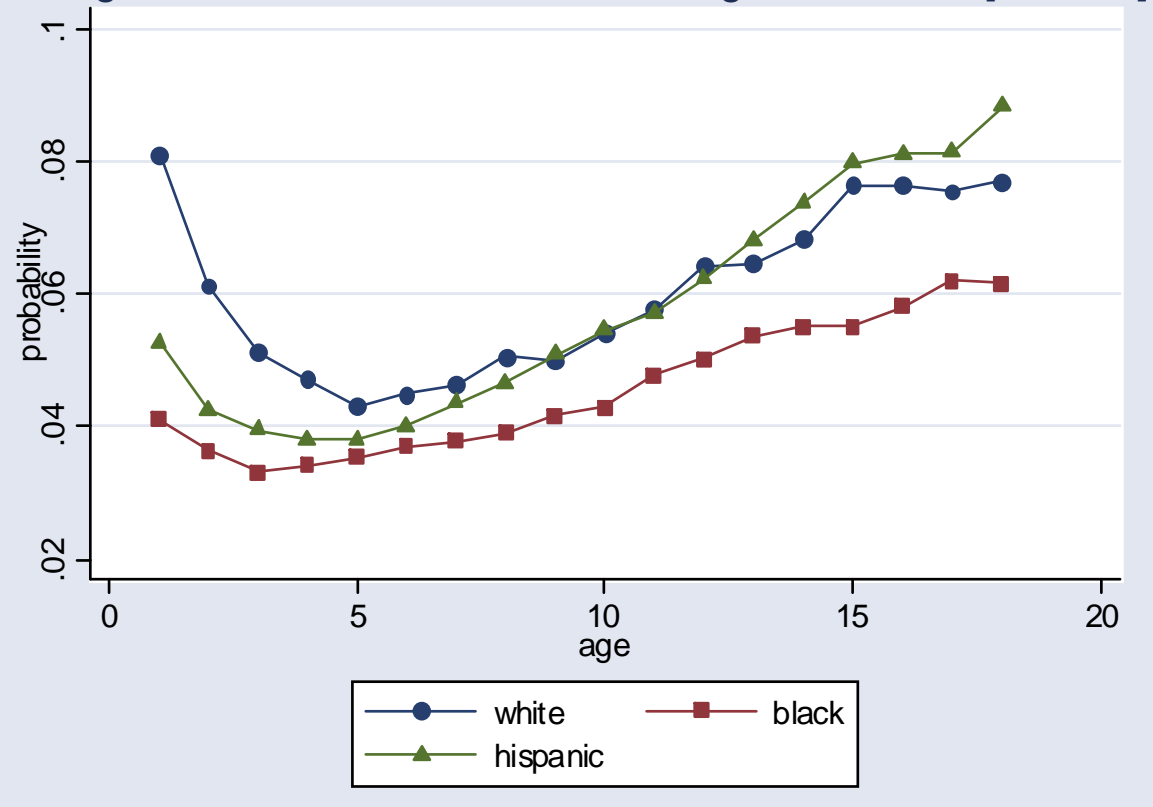

Figure 5d: Annual transition rate: cohabiting to single [if at risk]

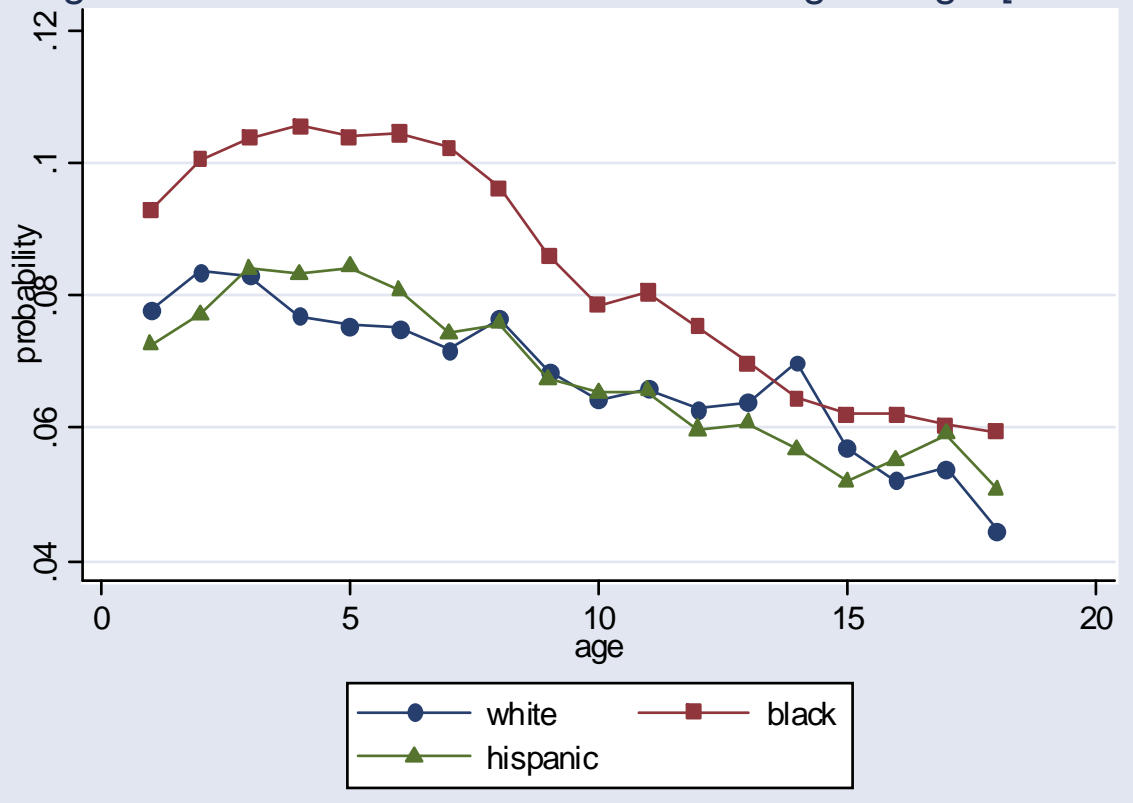


Figure 5e: Annual transition rate: married to single [if at risk]

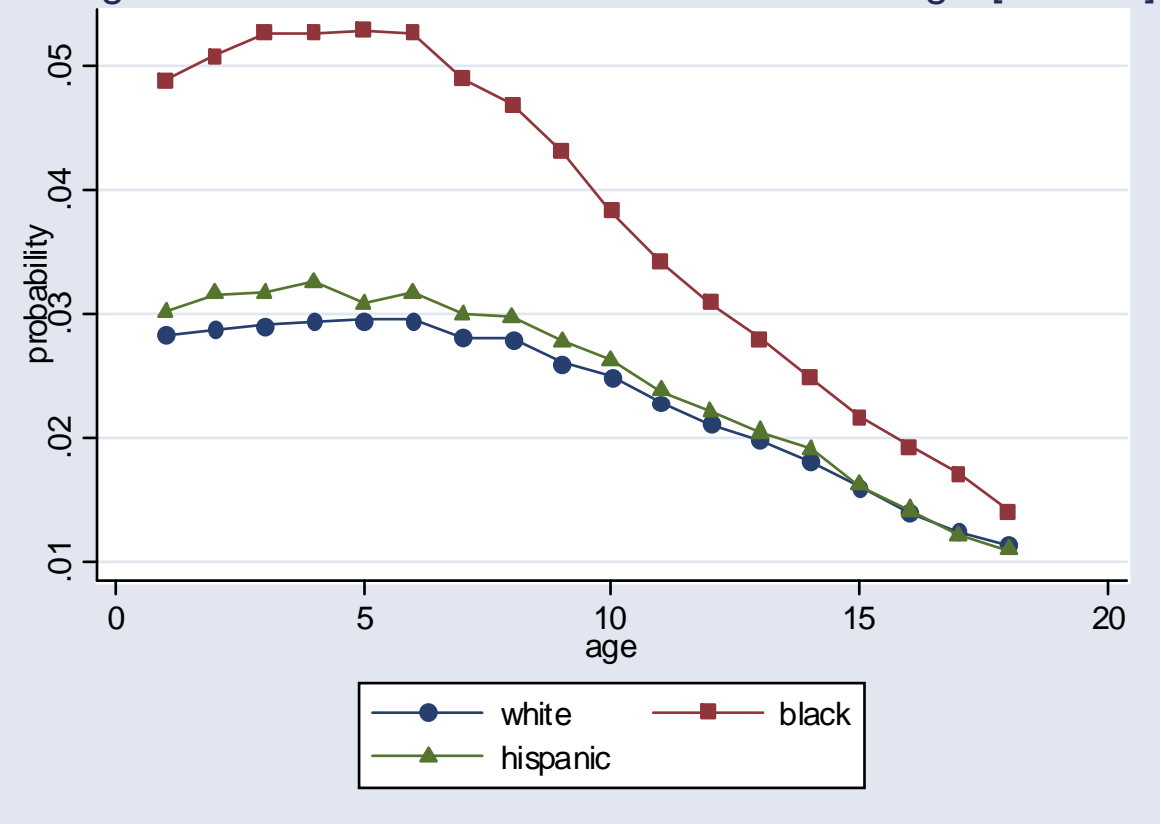


state 1 Single, not pregnant, $B_{t}=0$

\begin{tabular}{|c|c|c|c|}
\hline event: & $\begin{array}{l}\quad 2 \\
\text { Conceive, } \\
\text { new man } \\
\end{array}$ & $\begin{array}{l}5 \\
\text { Cohabit, } \\
\text { New man } \\
\end{array}$ & $\begin{array}{l}7 \\
\text { Marry, } \\
\text { New mar } \\
\end{array}$ \\
\hline $\begin{array}{l}\text { Intercept } \\
\text { Numfath }\end{array}$ & $\begin{array}{c}-14.745 \\
\left(\begin{array}{c}0.669)\end{array}\right)\end{array}$ & $\begin{array}{l}-20.637 \\
(\quad 0.715)\end{array}$ & $\begin{array}{c}-18.500 \\
(\quad 0.640)\end{array}$ \\
\hline Num marr. & $\begin{array}{c}-0.173 \\
(0.174)\end{array}$ & $\begin{array}{c}-0.283 \\
(0.111)\end{array}$ & $\begin{array}{c}-0.149 \\
(0.128)\end{array}$ \\
\hline Num cohab. & $\begin{array}{l}0.016 \\
(0.154)\end{array}$ & $\begin{array}{c}-0.146 \\
(0.086)\end{array}$ & $\begin{array}{c}-0.582 \\
(0.147)\end{array}$ \\
\hline Prev marr. & $\begin{array}{c}0.281 \\
(0.274)\end{array}$ & $\begin{array}{l}0.532 \\
(0.186)\end{array}$ & $\begin{array}{c}-0.733 \\
(0.234)\end{array}$ \\
\hline Prev. cohab. & $\begin{array}{l}0.226 \\
(0.268)\end{array}$ & $\begin{array}{l}0.723 \\
(0.173)\end{array}$ & $\begin{array}{c}-0.687 \\
(0.270)\end{array}$ \\
\hline
\end{tabular}

Age youngest

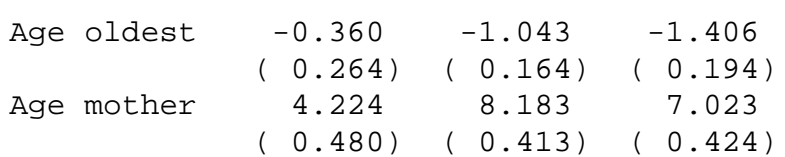
Dur. of cohab.

Dur. Single $\quad 1.591 \quad 1.133 \quad 1.710$ Agey sq.

Ageo sq.

$(0.266) \quad(0.171) \quad(0.226)$

Age mom sq.

$\begin{array}{ccc}-0.339 & 0.299 & 0.398 \\ (0.145) & (0.076) & (0.086) \\ -0.659 & -1.115 & -0.925 \\ (0.070) & (0.056) & (0.057)\end{array}$

Dur coh. sq.

Dur sing. sq. $-0.535-0.388-0.724$

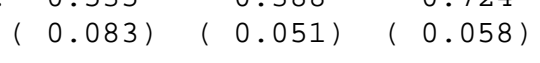

\begin{tabular}{|c|c|c|c|}
\hline Black & $\begin{array}{l}1.383 \\
(0.067)\end{array}$ & $\begin{array}{c}-0.789 \\
(0.074)\end{array}$ & $\begin{array}{c}-0.637 \\
(0.067)\end{array}$ \\
\hline Hispanic & 0.672 & -0.437 & 0.125 \\
\hline & $(0.091)$ & $(0.104)$ & $(0.067)$ \\
\hline Hisp*Prevmarr & $\begin{array}{l}0.192 \\
\left(\begin{array}{c}0.177 \\
)\end{array}\right.\end{array}$ & $\begin{array}{l}0.195 \\
(0.157)\end{array}$ & $\begin{array}{c}-0.256 \\
\left(\begin{array}{c}0.161)\end{array}\right)\end{array}$ \\
\hline
\end{tabular}

state 2

Single, not pregnant, $B_{t}>0$

\begin{tabular}{|c|c|c|c|c|c|}
\hline $\begin{array}{c}1 \\
\text { Conceive, } \\
\text { new man }\end{array}$ & $\begin{array}{l}\quad 2 \\
\text { Conceive, } \\
\text { cur.man }\end{array}$ & $\begin{array}{l}\quad 4 \\
\text { Cohab, } \\
\text { new man } \\
\end{array}$ & $\begin{array}{l}\quad 5 \\
\text { Cohab. } \\
\text { cur. man } \\
\end{array}$ & $\begin{array}{c}6 \\
\text { Marry, } \\
\text { new man } \\
\end{array}$ & \begin{tabular}{l}
\multicolumn{1}{c}{7} \\
Marry, \\
cur. man \\
\end{tabular} \\
\hline $\begin{array}{c}-4.046 \\
\left(\begin{array}{c}1.870)\end{array}\right.\end{array}$ & $\begin{array}{c}-8.113 \\
(\quad 2.256)\end{array}$ & $\begin{array}{l}-10.150 \\
(\quad 2.346)\end{array}$ & $\begin{array}{c}-14.295 \\
(\quad 2.231)\end{array}$ & $\begin{array}{c}-5.483 \\
(1.861)\end{array}$ & $\begin{array}{c}-10.255 \\
(\quad 2.994)\end{array}$ \\
\hline
\end{tabular}

\begin{tabular}{|c|c|c|c|c|c|}
\hline$\odot$ & 96 & -4 & 1. & -0. & 2 \\
\hline & 0.662 & $(0.645$ & $\odot .47 €$ & 1.11 & 0 \\
\hline & $-\odot$. & $-\odot$. & $-\odot$ & -1 & 8 \\
\hline & 0 & 0 & 0 & 0 & 7 \\
\hline . & 1.576 & 2.975 & 4.821 & $\begin{array}{l}1.095 \\
1.192\end{array}$ & $\begin{array}{l}2.475 \\
1.774\end{array}$ \\
\hline
\end{tabular}

$\begin{array}{lllll}(1.292)(1.370)(1.364) & (1.275)(1.192) & (1.774)\end{array}$ state 3

Cohabiting, not pregnant

\begin{tabular}{|c|c|c|}
\hline $\begin{array}{l}1 \\
\text { Conceive, } \\
\text { Cur. man }\end{array}$ & \begin{tabular}{c}
\multicolumn{1}{c}{3} \\
Become \\
single \\
\end{tabular} & $\begin{array}{c}6 \\
\text { Marry } \\
\text { cur. man } \\
\end{array}$ \\
\hline $\begin{array}{c}-1.967 \\
(1.321) \\
0.168 \\
(0.083)\end{array}$ & 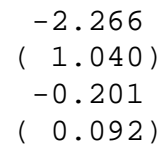 & 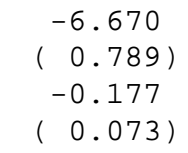 \\
\hline $\begin{array}{c}-0.203 \\
\left(\begin{array}{c}0.160)\end{array}\right)\end{array}$ & $\begin{array}{l}0.309 \\
\left(\begin{array}{l}0.095\end{array}\right)\end{array}$ & $\begin{array}{c}-0.139 \\
\left(\begin{array}{c}0.081)\end{array}\right)\end{array}$ \\
\hline
\end{tabular}

\begin{tabular}{|c|c|c|}
\hline$\odot .246$ & 0.302 & -0.292 \\
\hline$(0.462)$ & $(0.259)$ & $(0.188)$ \\
\hline-1.236 & -1.241 & 2.264 \\
\hline$(0.799)$ & $(0.597)$ & $(0.456)$ \\
\hline-0.737 & 2.378 & -2.331 \\
\hline$(0.617)$ & $(0.422)$ & $(0.329)$ \\
\hline $\begin{array}{c}-0.479 \\
\left(\begin{array}{c}0.323 \\
)\end{array}\right.\end{array}$ & $\begin{array}{c}-0.090 \\
\left(\begin{array}{c}0.124)\end{array}\right)\end{array}$ & $\begin{array}{l}0.152 \\
(0.091)\end{array}$ \\
\hline 0.101 & 0.110 & -0.324 \\
\hline$(0.119)$ & $(0.083)$ & $(0.065)$ \\
\hline$-\odot .151$ & -1.732 & $\odot .633$ \\
\hline$(0.572)$ & $(0.313)$ & $(0.287)$ \\
\hline
\end{tabular}

\begin{tabular}{|c|c|c|c|c|c|}
\hline 0.616 & $\odot .208$ & -0.766 & -0.815 & -0.952 & -0.741 \\
\hline 0.239$)$ & (0.237) & $(0.264)$ & $(0.198)$ & $(0.204)$ & $(0.260)$ \\
\hline & ๑. 028 & -0.112 & -0.129 & -0.717 & -0.586 \\
\hline 34$)$ & 0.297) & $(0.296)$ & $0.228)$ & $0.273)$ & $0.344)$ \\
\hline
\end{tabular}

\begin{tabular}{|c|c|c|}
\hline 0.3 & 0.318 & $-\odot$. \\
\hline & $\theta$ & $(0$ \\
\hline & $\odot$. & $-\odot$ \\
\hline ○. & $(0.126$ & $(0.090$ \\
\hline
\end{tabular}




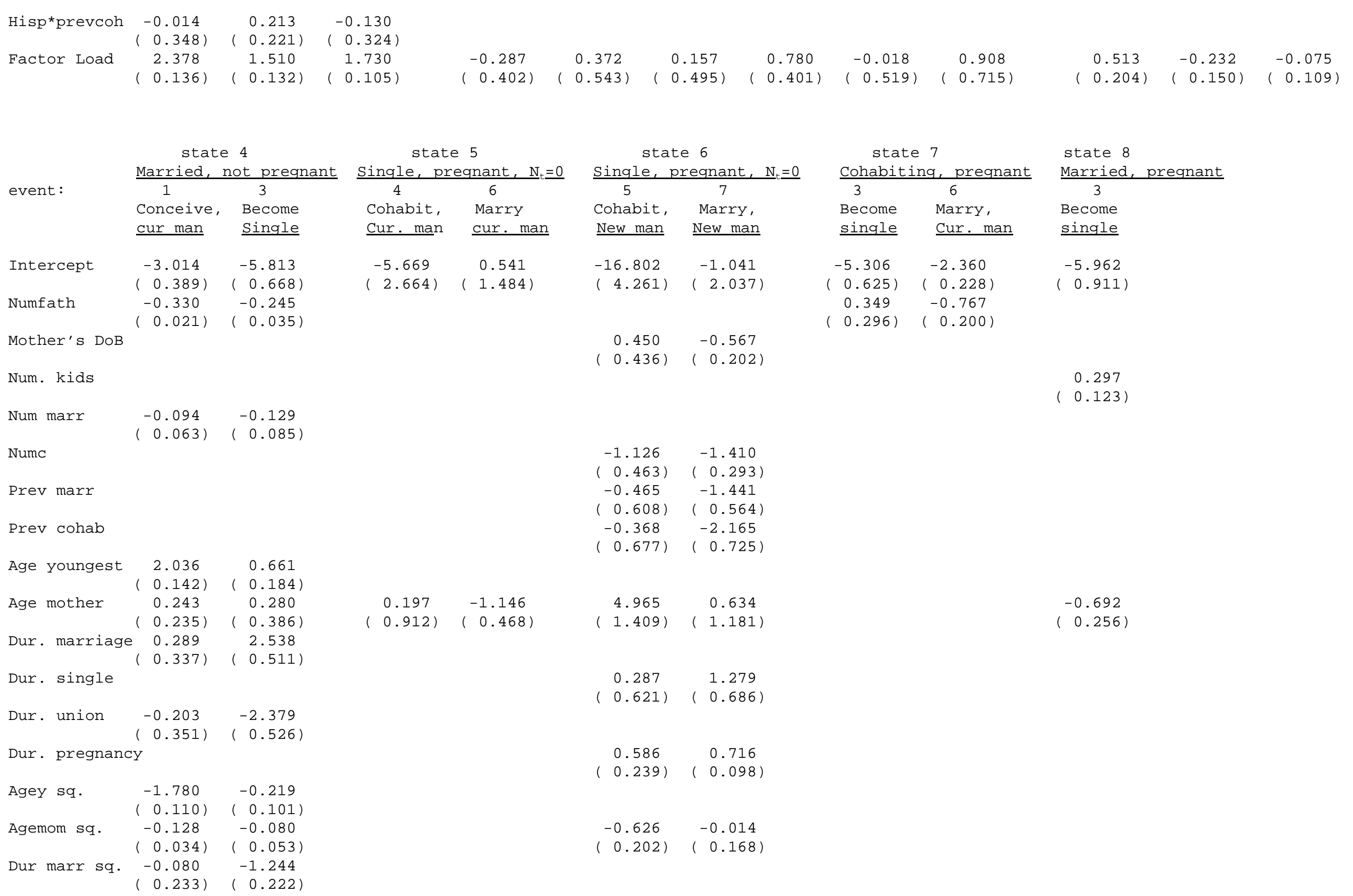


Dur single sq.

Dur union sq. -0.329

1.039

$(0.237)$

$\odot .222$

Dur preg sq.

Dur preg $=1$

Black

$-0.115$

$(0.055)$

0.532

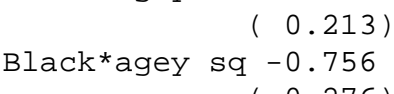

$-0.152)$
-0.123

Hispanic

0.120

$(0.038)$

$(0.284)$

0.088

Hisp*prevmarr

Hisp*prevcoh

$\begin{array}{lll}\text { Factor Load } & -0.490 & 0.609 \\ (0.066) & (0.113)\end{array}$

Prob. weight 0.509

$$
(0.071)
$$

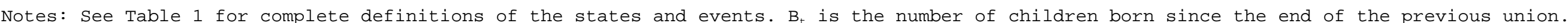
$\mathrm{N}_{\mathrm{t}}=\odot$ if the current pregnancy is with the current man, and $\mathrm{N}_{\mathrm{t}}=1$ if it is with a new man.

DoB = Date of Birth.

Numfath = number of children fathered by the current man (currently in a union).

Numc = number of children fathered by the current man (not currently in a union).

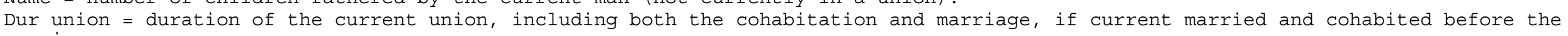
marriage.

Prev marr $=1$ if the union status before the current single spell was married.

Prev cohab $=1$ if the union status before the current single spell was cohabitation.

Dur preg $=1$ is a dummy if currently in the first month of a pregnancy.

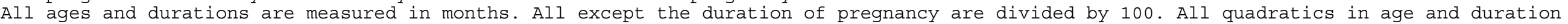
(except pregnancy) are divided by 10000 .

The mother's date of birth is measured in months since January 1900, divided by 100

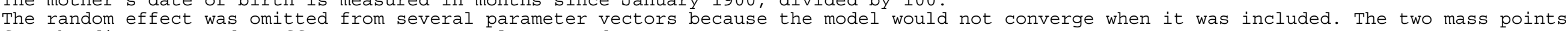
for the discrete random effect were set equal to 0 and 1 .
$-0.683$
$\begin{array}{cc}-0.075 & -0.091 \\ 0.028) & (0.011)\end{array}$

$\begin{array}{ccccc}-1.520 & -2.028 & -0.024 & -0.992 & 1.263 \\ 0.299) & (0.136) & (0.855) & (0.220) & (0.304)\end{array}$

$0.120 \quad 1.264$

$(0.262) \quad(0.469)$

tecte 
Table A-2: Comparison of Selected Statistics from the Data with Simulations from the Estimated Model

\begin{tabular}{|c|c|c|c|c|c|c|}
\hline \multirow[b]{2}{*}{ Mothers } & \multicolumn{2}{|c|}{ White } & \multicolumn{2}{|c|}{ Black } & \multicolumn{2}{|c|}{ Hispanic } \\
\hline & data & model & data & model & data & model \\
\hline Ever married & 88.6 & 91.5 & 61.2 & 71.6 & 80.7 & 88.1 \\
\hline Ever ended marriage, if ever married & 37.2 & 38.2 & 52.3 & 44.5 & 42.1 & 39.1 \\
\hline Ever married more than once, if ever ended marriage & 60.5 & 53.3 & 30.0 & 27.8 & 49.3 & 45.4 \\
\hline Ever cohabited & 42.2 & 44.9 & 34.6 & 43.1 & 37.3 & 40.1 \\
\hline Ever moved from cohabitation to marriage & 34.7 & 37.2 & 21.2 & 29.3 & 24.8 & 28.9 \\
\hline Number of children ever born $=0$ & 21.7 & 19.0 & 18.2 & 15.8 & 16.9 & 14.0 \\
\hline Mean number of children ever born & 1.69 & 1.65 & 1.87 & 1.76 & 1.98 & 1.92 \\
\hline Ever had children living with no man, if ever had kids & 36.5 & 41.1 & 82.3 & 81.5 & 52.4 & 52.1 \\
\hline Ever had children with a stepfather present, if ever had kids & 24.2 & 27.9 & 35.6 & 45.7 & 29.5 & 34.4 \\
\hline Age at first birth & 25.1 & 24.8 & 21.7 & 22.2 & 23.2 & 23.7 \\
\hline \multicolumn{7}{|l|}{ Children } \\
\hline \multicolumn{7}{|l|}{ Mother's marital status at conception: } \\
\hline Single & 15.7 & 16.4 & 63.9 & 64.6 & 27.5 & 28.0 \\
\hline Cohabiting & 4.6 & 4.9 & 5.2 & 4.9 & 5.8 & 5.5 \\
\hline Married & 79.8 & 78.7 & 31.0 & 30.5 & 66.7 & 66.5 \\
\hline \multicolumn{7}{|l|}{ Mother's marital status at birth: } \\
\hline Single & 8.2 & 8.9 & 58.8 & 59.7 & 20.2 & 20.3 \\
\hline Cohabiting & 2.8 & 3.6 & 5.3 & 5.3 & 5.6 & 6.0 \\
\hline Married & 88.9 & 87.5 & 36.0 & 35.0 & 74.2 & 73.7 \\
\hline Conceived while single: percent born in cohabitation & 5.7 & 6.4 & 2.4 & 2.3 & 6.1 & 6.2 \\
\hline Conceived while single: percent born in marriage & 46.5 & 42.9 & 7.8 & 6.8 & 25.2 & 24.3 \\
\hline Conceived in cohabitation: percent born in marriage & 54.4 & 46.2 & 21.3 & 17.7 & 28.1 & 22.1 \\
\hline Ever lived with no father & 30.1 & 33.4 & 75.7 & 75.5 & 43.3 & 43.6 \\
\hline Ever lived with stepfather & 17.1 & 23.3 & 26.8 & 43.7 & 22.6 & 29.8 \\
\hline Ever lived with biological father & 94.0 & 93.8 & 51.6 & 56.2 & 84.7 & 85.5 \\
\hline Ever lived with cohabiting father & 13.5 & 18.4 & 25.9 & 37.6 & 22.3 & 26.3 \\
\hline Biological father ever moved in (if not present at birth) & 27.4 & 10.5 & 17.8 & 23.4 & 23.6 & 15.7 \\
\hline Biological father ever moved out (if ever present) & 24.3 & 29.7 & 43.3 & 39.4 & 29.4 & 31.4 \\
\hline Step father ever moved in (if biological father ever not present) & 52.6 & 73.5 & 34.9 & 64.1 & 50.3 & 72.5 \\
\hline Step father ever moved out (if ever present) & 36.5 & 32.4 & 51.2 & 38.6 & 36.8 & 33.5 \\
\hline
\end{tabular}

Observations from the data are weighted by the inverse of the number of distinct event histories per woman. The simulations go up to age 39 of women and age 18 of children. All figures are percentages except number of children born and age at first birth. In cases in which the date of an event is uncertain, the earliest possible date is used to compute the statistics in the data columns. However, this has very little impact on the statistics; we re-computed the statistics using the latest possible date, and they were always within one percentage point of the statistics shown in the table, and usually were identical. 


\section{Unpublished Appendix for Referees}

A Demographic Analysis of the Family Structure Experiences of Children in the United States

Likelihood Function and modifications to deal with uncertainty about sequences, dates, etc.

\section{Basic Likelihood Function}

Changing notation a bit from the text, let the index function $h_{j s}(t)$ for the occurrence of event $j$ in month $t$ while in state $s$ be given by $h_{j s}(t)=Z(t) \alpha_{j s}+X \beta_{j s}+\rho_{\mathrm{js}} \mu$. Consider a spell in state $s$ that began in month $t$ and ended in month $n$ with the occurrence of event $j$, one of the subset $J_{s}$ of the 7 risks listed in the last column of Table 1 . Use the convention that the month in which the transition occurred is the last month in which state $s$ was occupied, and the following month is the first month in which the new state $s^{\prime}(s, j)$ is occupied. Note that the state $s^{\prime}$ occupied in the subsequent spell depends on both the event $j$ that occurred to end the spell and the state $s$ occupied. Given the assumption of the logit functional form, the probability that event $j$ occurs while in state $s$ in month $t$, (conditional on $Z(t), X$, and $\mu$; the conditioning is sometimes left implicit) is given by

$$
P_{j s t}=\exp \left\{h_{j s}(t)\right\} /\left(1+\sum_{k \in J_{s}} \exp \left\{h_{k s}(t)\right\}\right)
$$

and the probability that no event occurs in month $t$ is

$$
P_{0 s t}=1 /\left(1+\sum_{k \in J_{s}} \exp \left\{h_{k s}(t)\right\}\right)
$$

If the spell is not censored, the likelihood function contribution for the spell in state $s$ is:

$$
L_{j s}(t, n, \mu)=\left[\prod_{\ell=\mathrm{t}}^{\mathrm{n}-1} P_{0 \mathrm{~s} \ell}\right] P_{j s n}
$$

If the spell is censored at month $n$, the last term is dropped and the upper limit of the product is 
$n$.

Consider a woman who experiences a total of $A$ spells. The $m^{\text {th }}$ spell begins in calendar month $t(m)$ and ends in calendar month $n(m)$. The state occupied in spell $m$ is $s(m)$, and the event causing the $m^{\text {th }}$ spell to end is $j(m)$. For simplicity, assume that none of the spells is censored except the last. The likelihood contribution for the A spells observed for a given woman conditional on $\mu$ is

$$
L(\mu)=\left[\prod_{m=1}^{\mathrm{A}-1} L_{j(m) s(m)}(t(m), n(m), \mu)\right] L_{s(A)}(t(A), n(A), \mu),
$$

and the unconditional likelihood contribution for the woman is

$$
L=\sum_{\mathrm{c}=1}^{C} \pi_{\mathrm{c}} \mu_{\mathrm{c}}
$$

where $\mu_{\mathrm{c}}$ is the $c^{\text {th }}$ point of support in the discrete distribution of $\mu, \pi_{\mathrm{c}}$ is the corresponding probability, and there are $C$ points of support.

We now describe how the likelihood function is modified to deal with uncertain dates and sequences of events.

(1) The month in which an event occurred is unknown. Suppose the month in which event $j$ occurred during spell $m$ in state $s$ is not observed. We know only that the event occurred between month $n$ and month $q$. In the standard case in which the month $(n)$ in which the event occurred is known, the likelihood contribution for the pair of spells $m$ and $m+1$ is part of the product in equation (1). Assuming for simplicity that spell $m+1$ is censored (at date $n(m+1)$ ), this is given by

$$
L(m, m+1, \mu)=L_{j s}(t, n, \mu) L_{s^{\prime}}(n+1, n(m+1), \mu)
$$

where $s$ 'is the state occupied in spell $m+1$. If we know only that the event occurred between 
month $n$ and month $q$, then the likelihood contribution for the pair of spells is

$$
L(m, m+1, \mu)=\sum_{a=m}^{q} L_{j s}(t, a, \mu) L_{s^{\prime}}(a+1, n(m+1), \mu)
$$

(2) The sequence in which events occurred is uncertain. To illustrate this case, suppose the exact month in which a cohabitation began is unknown, but it is known to have begun between months $n$ and $q$. And a child was conceived in month $o$, where $n<o<q$. Then we do not know whether the child was conceived before the cohabitation began or after. In this case there are two events and three spells to consider: $m$ (single, not pregnant), $m+1$ (either cohabiting and not pregnant or single and pregnant) and $m+2$ (cohabiting and pregnant). Let $j$ denote the decision to cohabit and let $\mathbf{j}$ represent conception of a child. Further, let $s$ denote the state occupied in spell $m$, and $s^{\prime}(j(m), s)$ the state occupied in spell $m+1$ if the event that terminates spell $m$ is $j(m)$, and $s^{\prime \prime}\left(j(m+1), s^{\prime}\right)$ the state occupied in spell $m+2$ if the event that terminates spell $m+1$ is $j(m+1)$. Suppose for illustration that spell $m+2$ is the last spell, and as before let $n(m+2)$ denote the censoring date for spell $m+2$. Then the likelihood contribution for the three spells is

$$
\begin{aligned}
& L(m, m+1, m+2, \mu)=\underset{a=n}{\left[\sum_{a=n}^{o-1} L_{j s}(t, a, \mu) L_{j s^{\prime}(\mathrm{s}, \mathrm{j})}(a+1, o)\right] L_{s^{\prime \prime}\left(s^{\prime}, j\right)}(o+1, n(m+1), \mu)} \\
& +L_{j s}(t, o, \mu)\left[\sum_{a=o+1}^{q} L_{j s^{\prime}(s, j)}(o, a, \mu) L_{s^{\prime \prime}\left(s^{\prime}, \mathrm{j}\right)}(a+1, n(m+1), \mu)\right]
\end{aligned}
$$

The first line accounts for the probability that the cohabitation began before the conception occurred $(c<o)$. The second line accounts for the probability that the cohabitation began after the conception occurred $(c>o)$. Note that only one event can occur in a given month.

(3) A woman with $B_{t}>0$ gets pregnant but we cannot determine from the data whether it is with the current man (father of the most recent of the $B_{t}$ children) or a new 
man. In this case, we know that in a given month either event 1 or event 2 occurred, but we do not know which. Suppose the pregnancy occurred in month $q$ in spell $z$. The likelihood contribution for the woman in this case is

$$
\begin{aligned}
& L(\mu)=\left[\prod_{m=1}^{z-1} L_{j(m) s(m)}(t(m), n(m), \mu)\right. \\
& *\left\{L _ { 1 s ( z ) } ( q , n ( z ) , \mu ) \left[\prod_{m=Z+1}^{A-1} L_{j(m) s(m)}(t(m), n(m), \mu \mid j=1) L_{s(A)}\left(t_{A}, n(A), \mu \mid j=1\right)\right.\right. \\
& +L_{2 s(z)}(q, n(z), \mu)\left[\prod_{m=Z+1}^{A-1} L_{j(m) s(m)}(t(m), n(m), \mu \mid j=2) L_{s(A)}\left(t_{A}, n(A), \mu \mid j=2\right)\right\},
\end{aligned}
$$

where $n(z-1)=q-1$ and the conditioning on $j=1$ and $j=2$ indicates that the entire subsequent demographic history may depend on which event occurred. 